WORKING PAPER - NO. 2020-156

Stock Prices, Lockdowns, and Economic Activity in the Time of Coronavirus

Steven J. Davis, Dingqian Liu, and Xuguang Simon Sheng

DECEMBER 2020

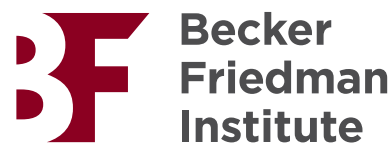




\title{
Stock Prices, Lockdowns, and Economic Activity in the Time of Coronavirus
}

\author{
Steven J. Davis ${ }^{*}$, Dingqian Liu ${ }^{\dagger}$ and Xuguang Simon Sheng*
}

15 October 2020, last edited on 29 December 2020

\begin{abstract}
Stock prices and workplace mobility trace out striking clockwise paths in daily data from midFebruary to late May 2020. Global stock prices fell 30 percent from 17 February to 12 March, before mobility declined. Over the next 11 days, stocks fell another 10 percentage points as mobility dropped 40 percent. From 23 March to 9 April, stocks recovered half their losses and mobility fell further. From 9 April to late May, both stocks and mobility rose modestly. This dynamic plays out across the 35 countries in our sample, with a few notable exceptions. We also find that stricter lockdown policies, both in-country and globally, drove larger declines in national stock prices conditional on pandemic severity, workplace mobility, and income support and debt relief policies. Looking more closely at the two largest economies, the pandemic had greater effects on stock market levels and volatilities in the U.S. than in China. Narrative evidence confirms the dominant - and historically unprecedented - role of pandemic-related developments for stock prices in both countries. The size of the global stock market crash in reaction to the pandemic is many times larger than a standard asset-pricing model implies.
\end{abstract}

JEL Classifications: E32, E44, E65, G12, G18, I18

Keywords: stock prices, lockdown policies, market shutdowns, coronavirus, COVID-19, workplace mobility, China

Acknowledgements: We thank Linda Tesar (editor), Stefano Giglio (discussant), Li Su (discussant), Francois Gourio, Prachi Mishra, Xiao Wang, Ivan Werning and participants at the IMF's 21st Jacques Polak Annual Research Conference and the Renmin University of China conference on "Structural Reforms and Economic Developments in the Face of Rising Uncertainty" for many helpful comments and suggestions. Davis thanks the U.S. National Science Foundation (SES 20180940), the Becker Friedman Institute at the University of Chicago, and the University of Chicago Booth School of Business for financial support.

\footnotetext{
*Booth School of Business, University of Chicago, USA, Steven.Davis@chicagobooth.edu

$\dagger$ Department of Economics, American University, USA, d15165a@american.edu

$¥$ Department of Economics, American University, USA, sheng@ american.edu
} 


\section{Introduction}

Stock markets cratered after mid-February in countries around the world, as the coronavirus pandemic spread beyond China. Value-weighted prices dropped 40 percent from 17 February to 23 March in the advanced economies (Figure 1). Emerging market and developing economies (EMDEs) saw an even steeper drop. This period also exhibits historically high levels of intraday, daily, and implied stock market volatilities against a backdrop of extraordinarily high economic uncertainty. ${ }^{1}$

Figure 1. Global Stock Prices, Percent Deviations from 17 February 2020

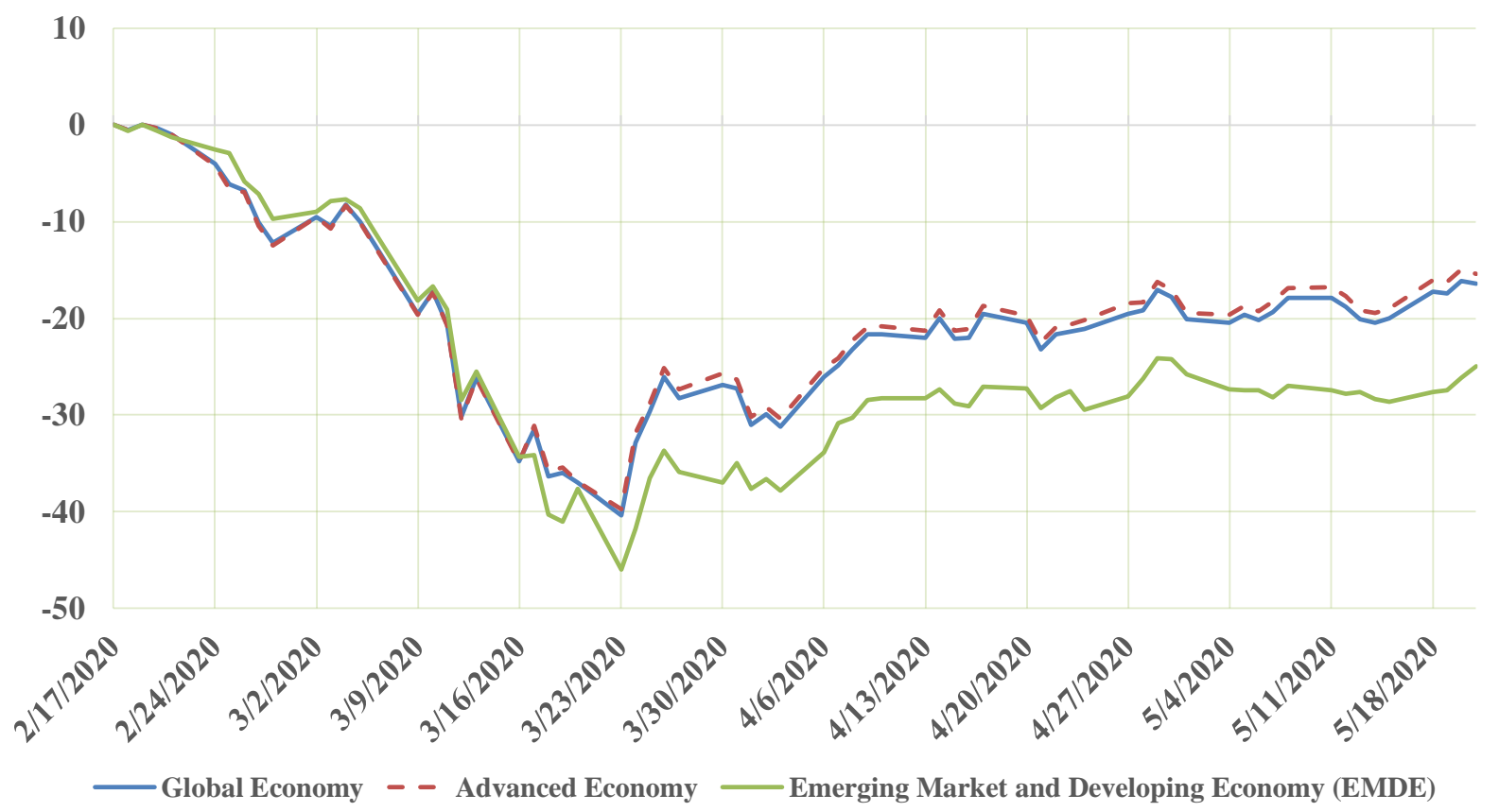

Notes: We plot the cumulative percent deviation in average equity prices from 17 February 2020 to the indicated dates. In computing averages, we weight each country's deviation by its market capitalization on 31 December 2018. Before averaging, we linearly interpolate country-level values between nearest trading dates to fill in missing values. Our sample contains 20 advanced economies (89.4\% of overall market capitalization) and 14 EMDEs (10.6\%) according to IMF's classification. We omit China in this plot but show it separately below.

In what many see as a puzzle, the global stock market recovered more than half its losses from 23 March to late May. U.S. stock market behavior, in particular, has prompted much head scratching: Despite a failure to control the pandemic, the U.S. stock market recovered 73 percent of its lost value by the end of May and 95 percent by $22 \mathrm{July}^{2}$ Shiller (2020) attributes these and

${ }^{1}$ See Alan et al. (2020) for equity market volatility measures based on GARCH models and intraday prices for dozens of countries, Baker et al. (2020a) for U.S. volatility measures that stretch back to 1900, the website at www.PolicyUncertainty.com for newspaper-based economic uncertainty measures for more than 25 countries based on Baker, Bloom and Davis (2016), and Altig et al. (2020) for a variety of forward-looking measures of economic uncertainty for the United States and United Kingdom.

${ }^{2}$ Calculated from the Wilshire 5000 Total Market Full Cap Index [WILL5000INDFC], retrieved from FRED, Federal Reserve Bank of St. Louis on 25 July 2020. Because U.S. markets were closed on 17 February, our start date is 18 February in these calculations. 
other aspects of recent market dynamics to "crowd psychology, the virality of ideas, and the dynamics of narrative epidemics."

Recent stock price behavior is also remarkable in other respects. Using text-based methods to characterize the drivers of stock market jumps and volatility, Baker et al. (2020a) find that previous pandemics, including the Spanish Flu, had modest effects on the U.S. market. In one exercise, they examine all 1,143 daily U.S. stock market moves greater than 2.5 percent, up or down, since 1900. Next-day newspaper accounts attribute not a single jump before 2020 to pandemic-related developments. In glaring contrast, newspapers attribute 24 of 27 daily U.S. jumps between 24 February and 30 April to COVID-19 and policy responses to the pandemic. Other research also highlights the pandemic's impact on the stock market. For example, Alfaro et al. (2020) find that changes in the anticipated trajectory of COVID-19 infections predict next-day stock returns in the United States. Amstad et al. (2020) find that a "COVID-19 risk attitude" index derived from internet searches helps explain national stock market moves from midFebruary to late April. These studies help motivate our investigation into the joint dynamics of stock prices, economic activity, and policy actions during the coronavirus pandemic.

In our first set of results, we show that stock prices and workplace mobility (a proxy for economic activity) trace out striking clockwise paths in daily data from mid-February to late May 2020. Global stock prices fell 30 percent from 17 February to 12 March, before mobility declined. Over the next 11 days, stocks fell another 10 percentage points as mobility dropped 40 percent. From 23 March to 9 April, stocks recovered half their losses and mobility fell further. From 9 April to late May, both stocks and mobility rose modestly. The same dynamic plays out across the vast majority of the 35 countries in our sample, with a few notable exceptions that we highlight and discuss. While stock prices clearly foreshadow the pandemic-related drop in economic activity, the size of the market crash in reaction to the pandemic is many times larger than implied by standard asset-pricing models.

Common global dynamics are a pronounced feature of our data. Thus, we also ask whether national stock prices have predictive value for own-country economic activity, conditional on global developments. We find that they do. Another natural question is whether stock prices responded too slowly to information that presaged a pandemic-driven downturn. While we cannot rule out this possibility, we make several observations that suggest it was reasonable, as of early and mid-February 2020, for stock market investors to anticipate a modest impact of COVID-19 on economic activity and asset prices.

Perhaps because COVID-19 erupted first in China, the dynamic between stock prices and mobility played out differently there. In particular, China experienced coincident drops in stock prices and mobility during the early phase of its pandemic recession. The exact dynamics are obscured by an extended Spring Festival market closure in response to the pandemic. Unlike most other countries, our mobility measure for China returns to its pre-pandemic baseline by late April, and Chinese stock prices surpass pre-pandemic levels by the second half of April.

In another set of results, we find that stock prices are lower when countries impose more stringent market lockdown measures. This association survives the inclusion of controls for global average outcomes and common time effects. In our preferred specification - which includes controls for own-country and global average values of economic activity, pandemic 
severity, and government income support and debt relief measures - national stock prices are 3.0 percentage points lower when the own-country lockdown stringency index is one standard deviation higher and 4.7 points lower when the global average stringency index is one standard deviation higher. These are separate effects, and both are statistically significant.

We also look more closely at stock prices in the world's two largest economies. As we show in various ways, the COVID-19 pandemic had much larger effects on stock prices and return volatilities in the U.S. than in China. At least in part, the greater impact on American stock prices reflects China's greater success in containing the pandemic. However, the U.S. stock market shows greater sensitivity to pandemic-related developments long before it became evident that its early containment efforts would flounder. Using next-day newspaper accounts, we classify the (perceived) reasons for large daily moves in Chinese stock markets from 1990 onwards. Before COVID-19, leading Chinese newspapers attribute not a single such move (out of hundreds) to pandemic developments or news about infectious diseases. From 2 January to 30 April 2020, Chinese newspapers attribute all 6 daily stock market moves greater than $|3 \%|$ on the Shanghai Stock Exchange and all 8 daily moves greater than $|3.8 \%|$ on the Hang Seng to the economic fallout of the pandemic or policy responses to the pandemic. ${ }^{3}$ These results closely parallel findings in Baker et al. (2020a) for the United States, but the incidence of large daily moves in the U.S. stock market during the coronavirus pandemic is about four times greater.

Our study relates closely to a rapidly growing literature on the dynamics of stock prices, economic activity, and policy actions during the coronavirus pandemic. Notable contributions include Alan et al. (2020), Caballero and Simsek (2020), Chen and Spence (2020), Cox et al. (2020), Deb et al. (2020), Giglio et al. (2020), Gormsen and Koijen (2020), and Landier and Thesmar (2020). ${ }^{4}$ Relative to these papers, we contribute by documenting the predictive content of national stock prices for near-future economic activity and by providing evidence that stock prices fall sharply with the stringency of lockdown measures, conditional on a battery of controls for pandemic severity, mobility, and the generosity of income support and debt relief policies.

\section{Stock Prices and Economic Activity as the Pandemic Unfolded A. Sources of Data for National Outcomes}

We integrate data from multiple sources. Our main high-frequency proxy for national economic activity is the percent workplace mobility deviation from baseline in Google's COVID-19 Community Mobility Reports. This measure reflects the frequency and duration of visits to worksites relative to the own-country baseline. Google (2020) defines the baseline as the median value, for the corresponding day of the week, during the 5-week period from 3 January to

\footnotetext{
${ }^{3}$ One might worry that newspaper accounts merely reflect the prevailing narrative of the day rather than meaningful information about the true reasons for large daily stock market moves. Baker, Bloom, Davis and Sammon (2020b) address this issue at some length. They validate the newspaper-derived explanations in several ways. They also find that newspaper-based interpretations have predictive power for future stock market volatility, even when conditioning on a standard battery of controls for serial correlation in stock market volatility.

${ }^{4}$ Another rapidly growing literature explores the distinctive effects of the coronavirus pandemic on the cross-sectional structure of firm-level equity returns. Examples include Albuquerque et al. (2020), Alfaro et al. (2020), Davis, Hansen and Seminario (2020), Ding et al. (2020), Hassan et al. (2020), Pagano et al. (2020), Papanikolaou and Schmidt (2020), and Ramelli and Wagner (2020).
} 
6 February 2020. These data are available from 17 February onwards for 34 countries in our many-country sample but not available for China.

We obtain national stock market index values on trading days from Global Financial Data (GFD) at https://globalfinancialdata.com/ and other sources. For much of our analysis, we treat each country's value on 17 February 2020 as a baseline and measure percent deviations on date $t$ as $r_{c, t}=\ln \left(\frac{P_{c, t}}{P_{c, 0}}\right) \times 100$, where $P_{c, 0}$ is the stock market index value of country $c$ on 17 February. When aggregating over countries, we weight by stock market capitalization values as of 31 December 2018 from the World Bank's World Federation of Exchanges Database.

To quantify the strictness of government-mandated market lockdown measures adopted in response to actual and prospective COVID-19 outbreaks, we use the Oxford "Stringency" Index from Hale (2020). Our Economic Support Index, which reflects the extent of government measures to provide income support and debt relief, is also from Hale (2020). Our data on COVID-19 cases and deaths per million persons are from Johns Hopkins University (2020).

After merging these sources, we have daily data for 34 countries from 17 February to 21 May 2020. Ordered by stock market capitalization, there are 20 Advanced Economies (AE) in our sample: The United States, Japan, United Kingdom, France, Canada, Switzerland, Germany, Australia, South Korea, Netherlands, Spain, Singapore, Sweden, Belgium, Taiwan, Poland, Ireland, New Zealand, Greece, Slovenia. There are 14 Emerging Market and Developing Economies (EMDEs): India, Brazil, South Africa, Thailand, Malaysia, Mexico, Chile, Qatar, Turkey, Romania, Argentina, Kazakhstan, Hungary, Croatia. ${ }^{5}$ We also have stock price data for China, which we merge to a different source of data on mobility, as discussed below.

Figure 2 displays percent workplace mobility deviations (WMD) for selected countries and regions. We linearly interpolate WMD values between market trading days to remove the effects of weekends and holidays. (Figure A.1 displays raw WMD values.) Most countries experienced tremendous drops in economic activity after early March. From 9 March to 9 April, the weighted-average WMD value fell nearly half among the AEs and nearly 60 percent among the EMDEs. Figure 2 also shows the WMD path for three "outlier" countries with relatively small drops in economic activity: Japan, Sweden and South Korea.

Figure 3 and Appendix Figure A.2 summarize the stringency of market lockdown measures adopted by governments in reaction to the pandemic, as quantified in Hale (2020). These figures show that the timing and severity of lockdowns differ substantially across countries. The pandemic emerged first in China, and China also clamped down on economic activity sooner than other countries. South Korea, Japan, and Taiwan also responded faster than most other AEs but more lightly in Japan and Taiwan. Sweden responded later than other AEs and with relatively light restrictions. Except for Japan, Sweden, South Korea, Singapore and Taiwan, all countries in our sample eventually implemented a hard lockdown for at least one week, where we interpret "hard" to mean a lockdown stringency index value of 70 or greater.

\footnotetext{
${ }^{5}$ Our grouping follows the IMF at www.imf.org/external/pubs/ft/weo/2020/01/weodata/groups.htm.
} 
Figure 2. Workplace Mobility on Trading Days, Percent Deviation from Baseline

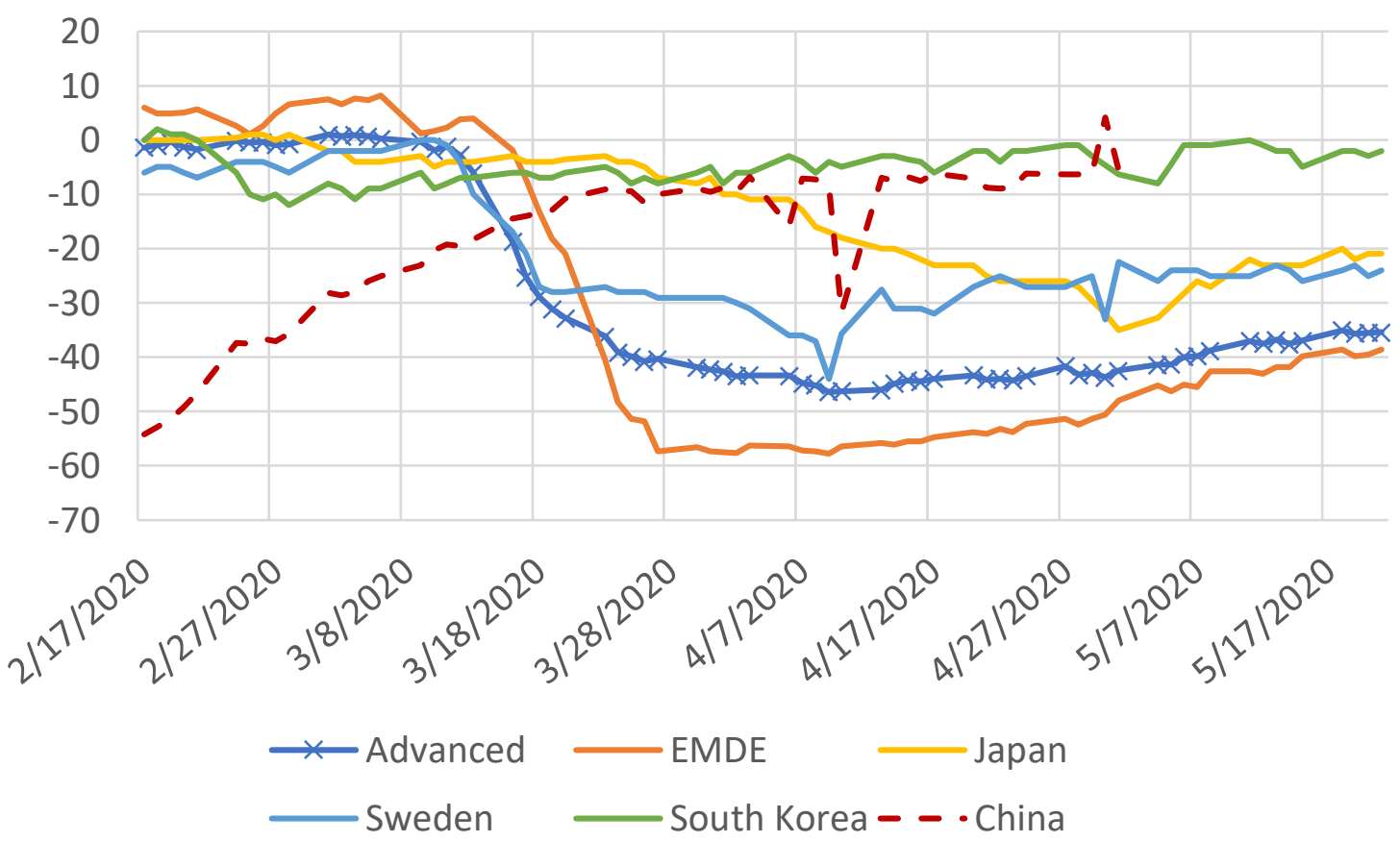

Note: We obtain national data from Google (2020) for trading days, interpolate the national data between trading days, and aggregate over countries using stock market capitalization. China's mobility data are from Baidu. China is not included in either Advanced economy or EMDE.

\section{B. The Time Paths of Stock Prices and Economic Activity}

Figure 4 shows that stock prices and workplace mobility trace out striking clockwise paths in daily data from mid-February to late May 2020. Global stock prices fell 30 percent from 17 February to 12 March, before mobility declined. Over the next 11 days, stocks fell another 10 percentage points as mobility dropped 40 percent. From 23 March to 9 April, stocks recovered half their losses and mobility fell further. From 9 April to late May, both stocks and mobility rose modestly. The same dynamic plays out across the vast majority of the 35 countries in our sample (Figure 5 and Figure A.3), with a few notable exceptions that we discuss later.

While our evidence shows that collapsing stock markets clearly preceded the collapse in economy activity, one could argue that a rational, forward-looking stock market would have reacted sooner. Indeed, Shiller (2020) writes: "[T]he World Health Organization (WHO) declared the new coronavirus 'a public health emergency of international concern' on January 30. Over the next 20 days, the S\&P 500 rose by $3 \%$, hitting an all-time record high on February 19. Why would investors give shares their highest valuation ever right after the announcement of a possible global tragedy? ... Why didn't the stock market "predict" the coming recession by declining before the downturn started?"

We take Shiller's question to be why didn't stock markets react earlier to the possibility of an impending economic disaster? And, in particular, why didn't markets react shortly after the WHO's declaration on 30 January? There is a ready answer to this question: Most investors did not see the novel coronavirus as a major risk to the economy of the sort that warranted a large 
devaluation in equity prices. Moreover, it is not obvious as of early February 2020, except in hindsight, that they should have regarded the virus as a major economic risk.

Figure 3. Economic Lockdown Stringency Index, 1 January to 21 May 2020.

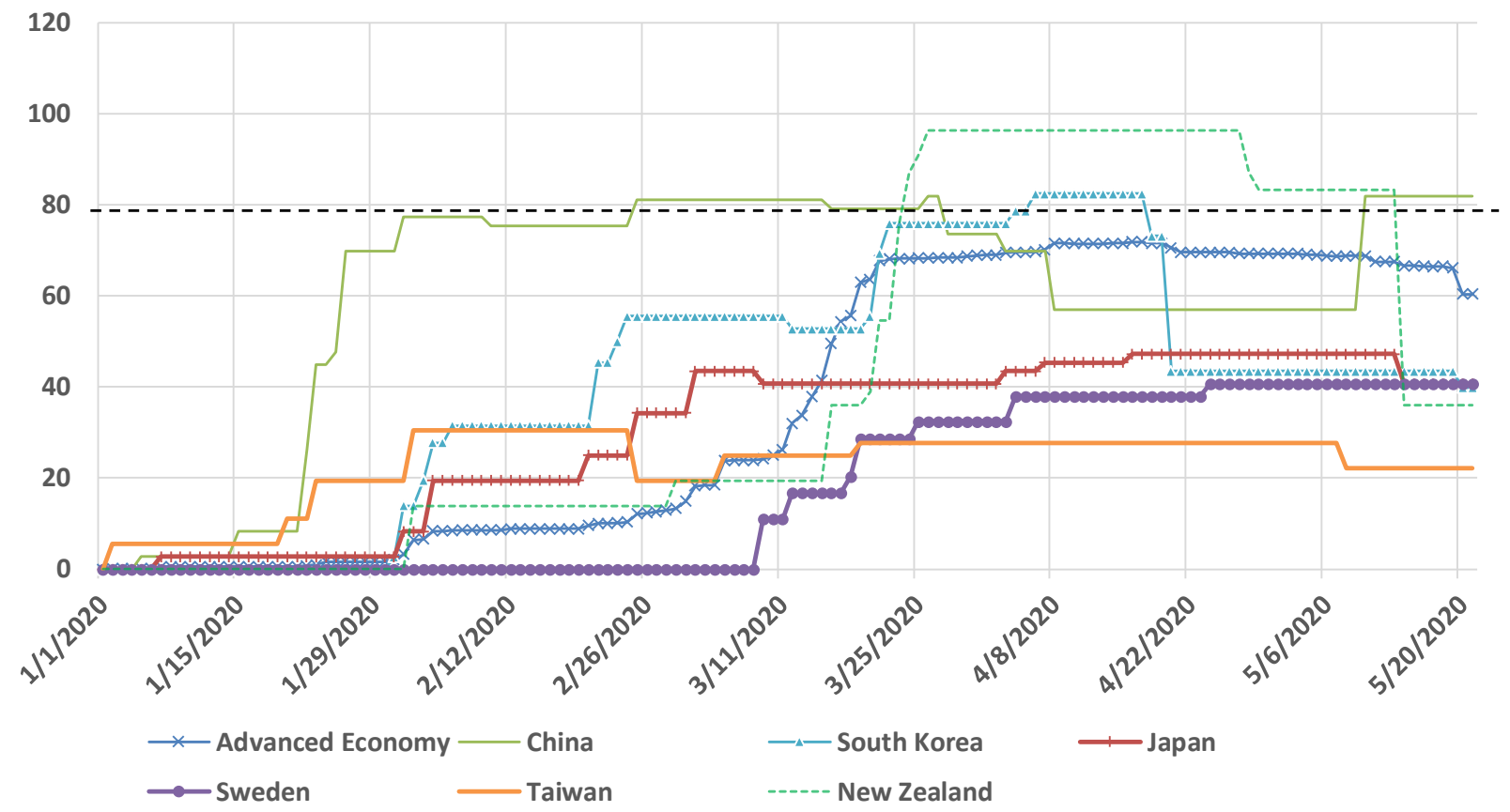

Note: We obtain national data from Hale (2020) and aggregate over countries using stock market capitalization. The stringency index exceeds 70 at some point for all countries except Japan, Sweden and Taiwan.

In this regard, we make four sets of observations. First, the WHO declared a "public health emergency of international concern" on five prior occasions since $2009 .{ }^{6}$ None of these declarations triggered a market crash, nor did any of the underlying disease outbreaks unfold in a manner that warranted a major devaluation in equity prices. Second, Baker et al. (2020a) show that no previous infectious disease outbreak over the previous 120 years affected the U.S. stock market in a manner that resembles its response to COVID-19. That includes the Spanish Flu of 1918-19, which involved a U.S. excess mortality rate five times that of COVID-19 to date. It also includes the influenza pandemic of 1957-58, which involved a U.S. excess mortality rate more than half that of COVID-19 to date. Third, we provide evidence below that no previous infectious disease outbreak (back to 1990) affected stock markets in mainland China and Hong Kong in a manner that resembles their responses to COVID-19. That includes the SARS outbreak in 2003. Fourth, at least in the United States, the economic contraction triggered by COVID-19 has been much deeper than one would anticipate by extrapolating the impact of previous pandemics over the past 120 years. ${ }^{7}$ These observations suggest it was reasonable, as of early and even mid-February 2020, for stock market investors to anticipate a modest economic impact of COVID-19 on economic activity and asset prices.

\footnotetext{
${ }^{6}$ See the Wikipedia entry for public health emergency of international concern, accessed 12 October 2020. The WHO formalized this type of emergency announcement in 2005, as discussed in WHO (2005).

${ }^{7}$ See Baker et al. (2020a), Ferguson (2020), and Velde (2020) on this point.
} 
Figure 4. Time Path of Stock Prices and Workplace Mobility from 17 February to 21 May 2020

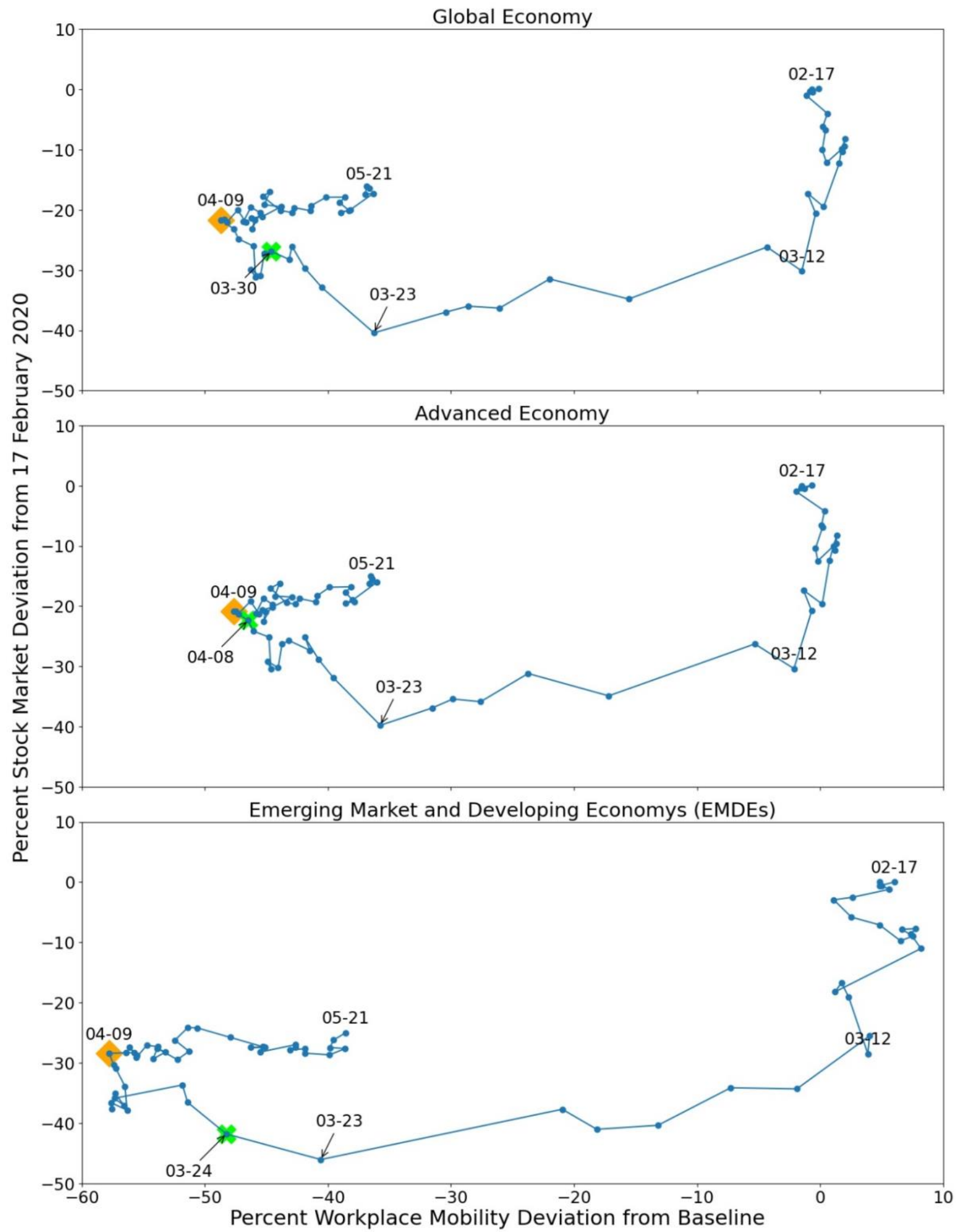

Note: The orange diamond marker highlights the date when the (weighted) global workplace mobility deviation from baseline reached its lowest value. The green cross highlights the first date when the weighted average lockdown stringency index first exceeds 70 . 
Figure 5. Time Path of Stock Prices and Workplace Mobility from 17 February to 21 May, Advanced Economies and EMDEs with Largest Market Capitalization (in parentheses)

United States (45.60\%)

10

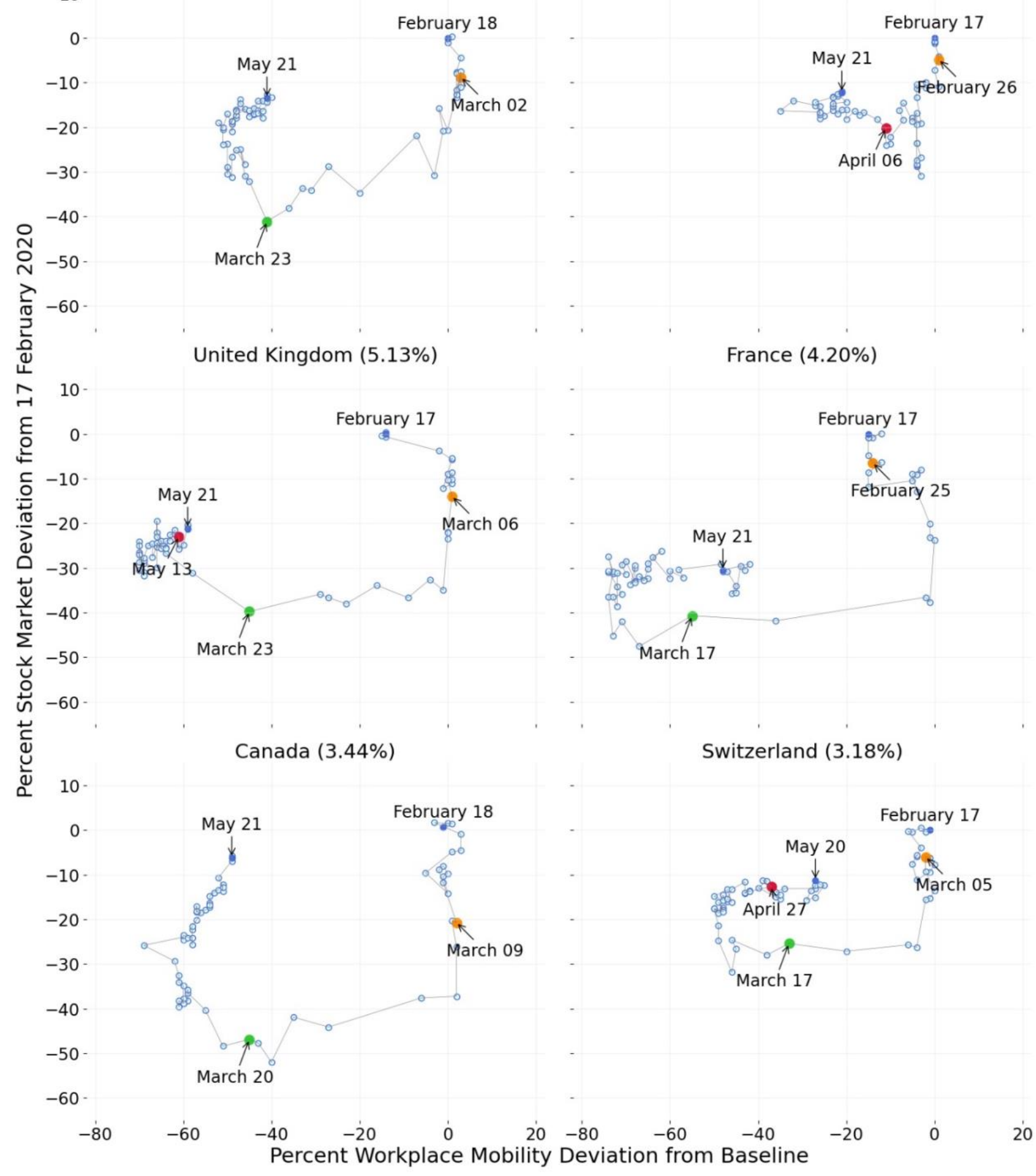


Germany (3.12\%)

$20-$

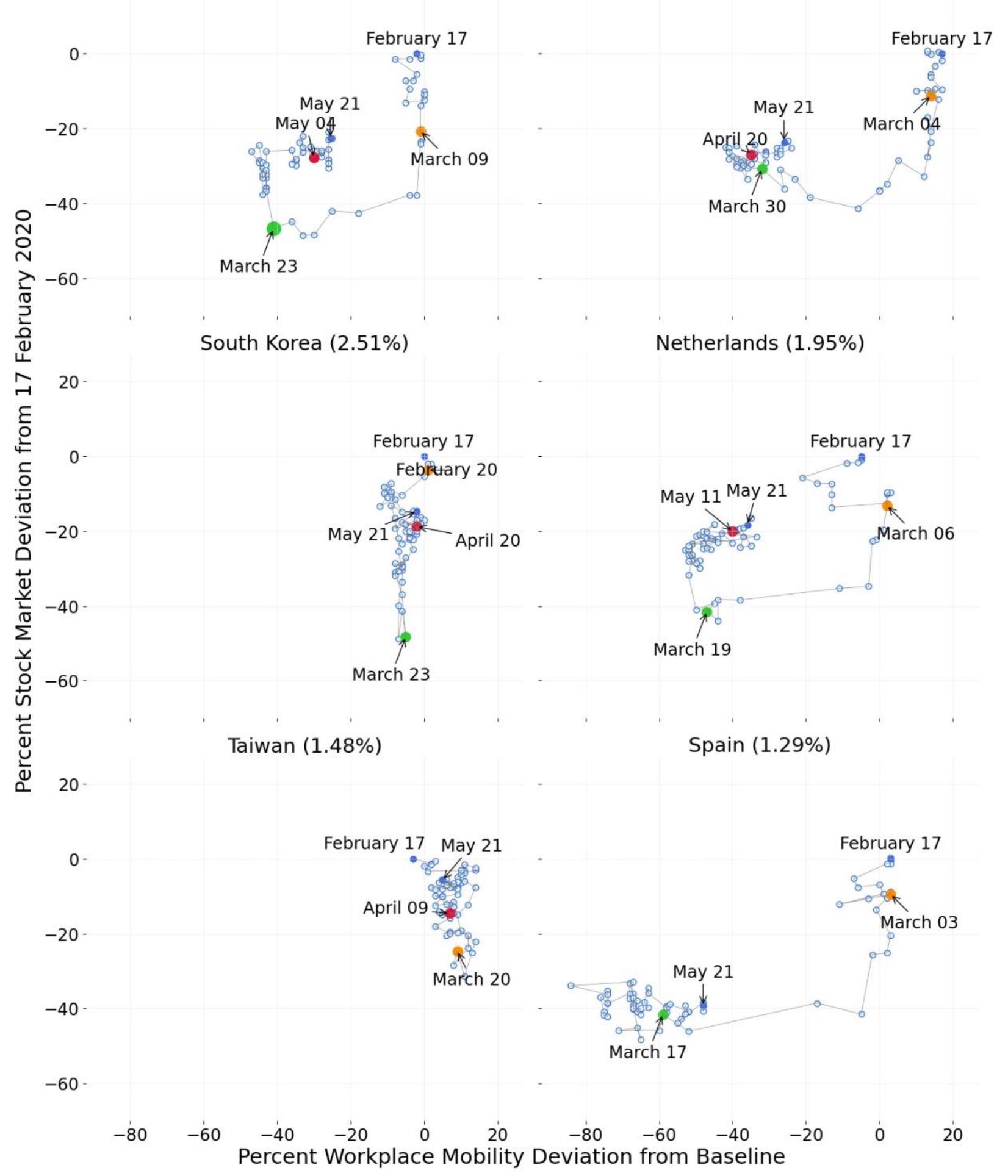

Australia (2.66\%) 


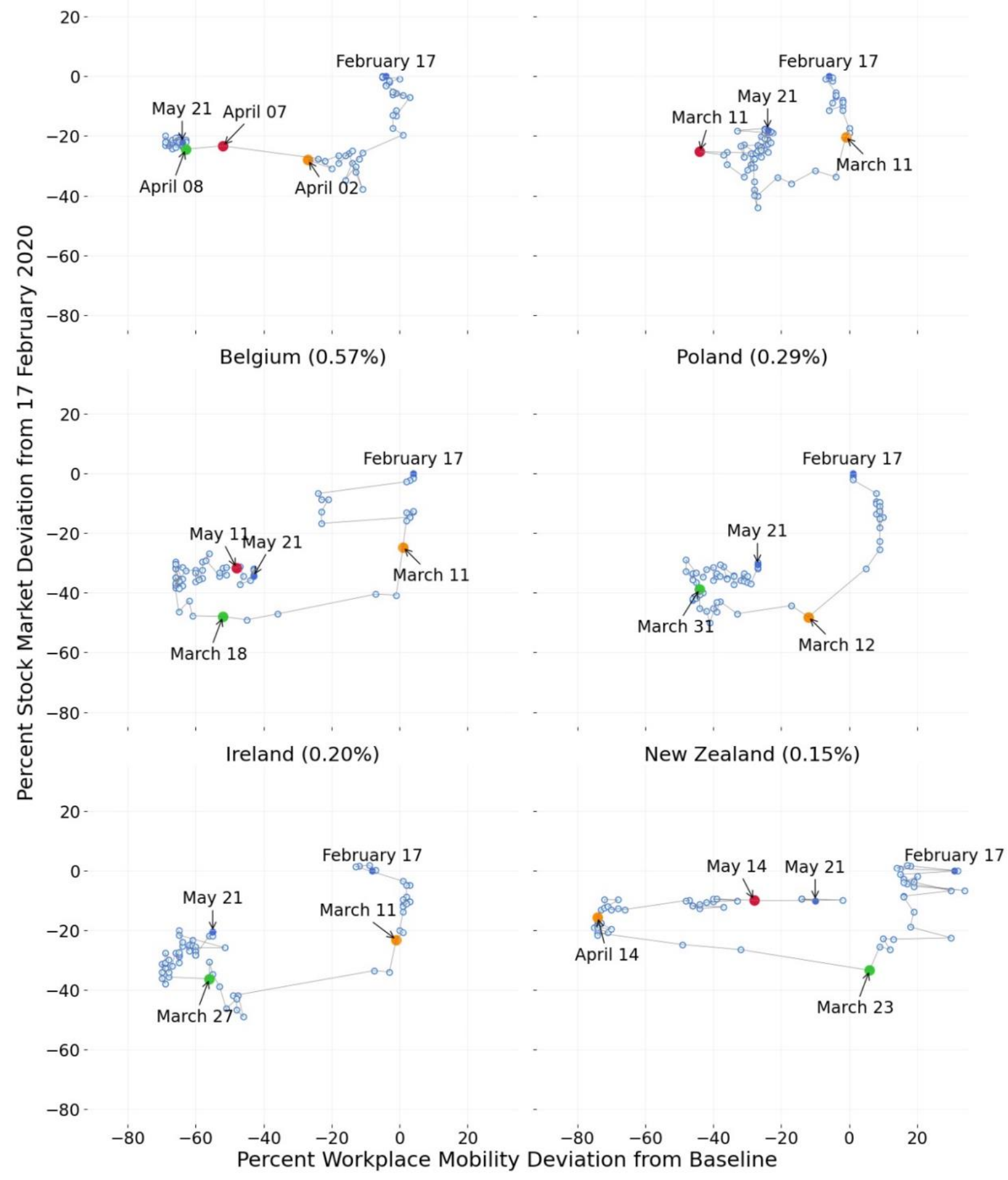

Note: An orange dot marks the first confirmed COVID-19 death in the country, a green dot marks the first date with a stringency index value of 70 or more, and a red dot marks the date on which the stringency index first drops below 70 . 


\section{National Stock Prices Predict Country-Specific Drops in Economic Activity}

As we have shown, national stock price movements exhibit important co-movements in the period during which global-average values collapse. That raises the question of whether national stock prices have predictive value for own-country economic activity, conditional on global developments. We take up that question now.

To do so, we regress workplace mobility deviations on lagged stock price deviations in our panel of 34 countries. Our sample for this analysis contains all workdays from 12 March to 23 March, where "workdays" refer to dates on which the country's stock market traded. For explanatory variables, we linearly interpolate between trading days to fill in weekend and holiday values. We choose 23 March as the sample endpoint, because that is when stock prices in most countries began to increase even as mobility fell further. We run two sets of regression:

$$
\begin{aligned}
& W M D_{c, t}=\alpha \times S M D_{c, t-1}+I_{c}+I_{t}+\varepsilon_{c, t} \\
& \Delta W M D_{c, t}=\sum_{j=1}^{6} \beta^{j} \times \Delta S M D_{c, t-j}+I_{t}+\varepsilon_{c, t}
\end{aligned}
$$

Table 1 reports the results. The first three columns provide strong statistical evidence that lower national stock prices yesterday foreshadow lower own-country workplace mobility deviations today. To interpret magnitudes, consider Column (3). The coefficient on the lagged own-country $S M D$ variable says: If yesterday's national stock price is 10 percentage points below its baseline value, the model predicts that today's mobility deviation is 3.7 percentage points below its baseline, conditional on common global developments. This is a large effect, especially in light of the fact that many countries in our sample experienced $S M D$ values 30 percentage points or more below baseline as of 22 March. $^{8}$

Columns (5)-(6) implement versions of regression (2) and confirm the predictive power of national stock prices for own-country economic activity during the mid-March period. In particular, the results say that changes in stock prices over the previous six days predict same direction changes in today's economic activity. To interpret magnitudes, consider Column (6). The results say that a one-percentage drop in national stock prices on each of the previous six trading days predicts a 6.4 percentage point drop in today's economic activity, as measured by $W M D$, conditional on common global developments. This is also a large effect.

Table 1. Regressions of Workplace Mobility Deviations on Lagged Stock Price Deviations, Daily Country-Level Data from 12 March to 23 March for the Dependent Variable

$W M D_{c, t}=$ Percent Workplace Mobility Deviation in Country $c$ on Trading Day $t$ $S M D_{c, t}=$ Percent Stock Price Deviation in Country $c$ on Trading Day $t$ $\Delta W M D_{c, t}=W M D_{c, t}-W M D_{c, t-1}$

\footnotetext{
${ }^{8}$ Column (4) shows a statistically insignificant coefficient on lagged SMD when controlling for country and time effects. Since our sample entails a short panel dimension, with at most 8 observations per country, the inclusion of country and time effects pushes the data very hard. In this regard, recall that both $S M D$ and $W M D$ are already demeaned at the country level, given that they are expressed relative to country-specific baselines. So, we do not think Column (4) is particularly informative. We include it here in case the reader has a different view.
} 


\begin{tabular}{|c|c|c|c|c|c|c|}
\hline \multirow{2}{*}{ Coefficient Estimates } & \multicolumn{4}{|c|}{ Dependent Variable: $W M D_{c, t}$} & \multicolumn{2}{|c|}{ Dependent Variable: $\Delta W M D_{c, t}$} \\
\hline & $(1)$ & $(2)$ & (3) & $(4)$ & $(5)$ & $(6)$ \\
\hline A & $\begin{array}{c}0.86^{* * * *} \\
(0.09)\end{array}$ & $\begin{array}{c}0.85^{* * *} \\
(0.09)\end{array}$ & $\begin{array}{c}0.37^{\text {*** }} \\
(0.08)\end{array}$ & $\begin{array}{l}-0.05 \\
(0.10)\end{array}$ & & \\
\hline$\sum_{j=1}^{6} \beta^{j}$ & & & & & $\begin{array}{l}1.50^{* * *} \\
(0.33)\end{array}$ & $\begin{array}{l}1.07^{* * *} \\
(0.33)\end{array}$ \\
\hline Intercept & $\begin{array}{l}8.22^{* *} \\
(3.35)\end{array}$ & & & & $\begin{array}{l}-0.56 \\
(1.15)\end{array}$ & \\
\hline Country Fixed Effects & $\mathrm{NO}$ & YES & $\mathrm{NO}$ & YES & $\mathrm{NO}$ & $\mathrm{NO}$ \\
\hline Time Fixed Effects & $\mathrm{NO}$ & $\mathrm{NO}$ & YES & YES & $\mathrm{NO}$ & YES \\
\hline $\begin{array}{l}\text { Observation Count } \\
\text { Adjusted } R^{2}\end{array}$ & $\begin{array}{l}265 \\
0.24\end{array}$ & $\begin{array}{l}265 \\
0.77\end{array}$ & $\begin{array}{l}265 \\
0.66\end{array}$ & $\begin{array}{l}265 \\
0.90\end{array}$ & $\begin{array}{l}265 \\
0.18\end{array}$ & $\begin{array}{l}265 \\
0.49\end{array}$ \\
\hline
\end{tabular}

Notes: The sample includes all workdays from 12 March to 23 March for 34 countries, where "workdays" refers to dates on which the country's stock market traded. For explanatory variables, we linearly interpolate between trading days to fill in weekend and holiday values. We use country-level stock price deviations prior to 12 March for lagged values of the explanatory variables. OLS Standard errors in parentheses.

${ }^{*} p<.1,{ }^{* *} p<.05,{ }^{* * *} p<.01$

\section{Can a Standard Asset-Pricing Model Rationalize the Size of the Market Crash?}

We now consider whether a standard asset-pricing model can rationalize the size of the stock market crash depicted in Figures 1, 4 and 5. We work with the rare-disaster model of Barro (2006), who builds on Lucas (1978), Mehra and Prescott (1985), and Rietz (1988). ${ }^{9}$ Earlier work using this type of model typically focuses on its implications for expected returns and the (expected) equity premium relative to the risk-free return. In contrast, we consider the model's implications for realized equity returns in reaction to a disaster.

Barro (2006) posits an endowment economy with a representative agent who has timeseparable, isoelastic preferences over the consumption good. Log output evolves exogenously as a random walk with drift:

$$
\ln \left(A_{t+1}\right)=\ln \left(A_{t}\right)+\gamma+u_{t+1}+v_{t+1}
$$

where the drift $\gamma \geq 0, u_{t+1}$ is i.i.d. normal with mean 0 and variance $\sigma^{2}$, and $v_{t+1}$ picks up lowprobability disaster shocks. Barro shows that the price of a one-period equity claim at $t$ is

$$
P_{t 1}=A_{t} e^{-\rho-(\theta-1) \gamma+(1 / 2)(\theta-1)^{2} \sigma^{2}} \times\left[e^{-p}+\left(1-e^{-p}\right) \times \mathrm{E}\left\{(1-b)^{1-\theta}\right\}\right]
$$

\footnotetext{
${ }^{9}$ Mehra and Prescott (1985) highlighted the equity return premium as a major puzzle for the standard representative-agent asset-pricing model set forth by Lucas (1978). Rietz (1988) showed that the puzzle could be resolved by allowing for a small probability of sufficiently big economic disasters. Barro (2006) advanced this idea by developing evidence on the frequency and size of economic disasters, calibrating an otherwise standard asset-pricing model to his evidence, and showing that it could rationalize the historical equity premium. Barro's article spurred many other investigations into the asset-pricing implications of rare disasters. See, for example, Gabaix (2012) and Wachter (2013) and references therein.
} 
where $\rho$ is the rate of time preference, $\theta$ is relative risk aversion, $\sigma$ is the standard deviation of the output growth rate absent disasters, E denotes the expectations operator, $p$ is the disaster probability, and $b$ is the size of the log output drop when disaster strikes. Disaster size is a random variable, which Barro calibrates to the empirical distribution of national economic disasters in the $20^{\text {th }}$ century. $\gamma, \sigma, p$ and other model parameters are known.

In taking this model to the data, we interpret 17 February as the last date before disaster strikes and 23 March as the date by which agents fully understand the gravity of the disaster. Global and U.S. equity prices fell about 40 percent (51 log points) over this 33 -day period. Using (3) and (4), the model-implied realized equity return over this period is

$$
\ln \left(\frac{P_{\text {after }}}{P_{\text {before }}}\right)=\ln \left(\frac{A_{\text {after }}}{A_{\text {before }}}\right)=\gamma\left(\frac{33}{365}\right)+\mathrm{u}_{1}-\left|\mathrm{v}_{1}\right|,
$$

where $\left|v_{1}\right|$ is the realized disaster size, and $\mathrm{u}_{1}$ is the realized value of the regular shock. ${ }^{10}$ For any reasonable values of the annual drift $(\gamma)$ and the variability of regular shocks $(\sigma)$, the first two terms on the right side of (5) are tiny compared to $v_{1}$. Thus, the model implies that stock prices fall nearly one-for-one in proportion to disaster size.

Figure 6 helps gauge the size of the COVID-19 disaster. The dashed line shows a log linear fit to data on U.S. real GDP per capita from 2014 Q1 through 2019 Q4 and its extrapolation through 2020 Q3. The maximal gap between the extrapolation and the actual path of real GDP per capita is about $12 \mathrm{log}$ points. We see this maximal gap as a loose upper bound on the perceived size of the disaster, given widespread expectations of rapid recovery once the pandemic comes under control and the strong partial bounce back in 2020 Q3. Evidence based on investor beliefs in Giglio et al. (2020), dividend strips in Gormsen et al. (2020), and projected corporate earnings in Landier and Thesmar (2020) all point to a disaster that is considerably smaller than $12 \log$ points. In short, it appears that stock market crash is at least four times as large as the disaster and perhaps ten times as large. Thus, the model cannot explain the size of the stock market crash from 17 February to 23 March as a reaction to the disaster.

One might think that combining the realized disaster with a surprise jump in the probability of a further disaster would bring the model closer to the data. In this case, $\ln \left(\frac{P_{\text {after }}}{P_{\text {before }}}\right)$ contains an extra term due to the change in the value of $p$ inside the bracketed expression on the right side of (4). Somewhat counterintuitively, however, the bracketed term in (4) rises with $p$ for $\theta>1$. Thus, postulating a global rise in $p$ cannot reconcile the model with the data. See Section IV in Barro (2006) for a related discussion. Gabaix (2012) shows how to overturn this result with Epstein-Zin preferences.

\footnotetext{
${ }^{10}$ Given the stochastic process in (3), the rates of return on one-period and full equity claims are identical.
} 
Figure 6. Assessing the Size of the COVID-19 Disaster

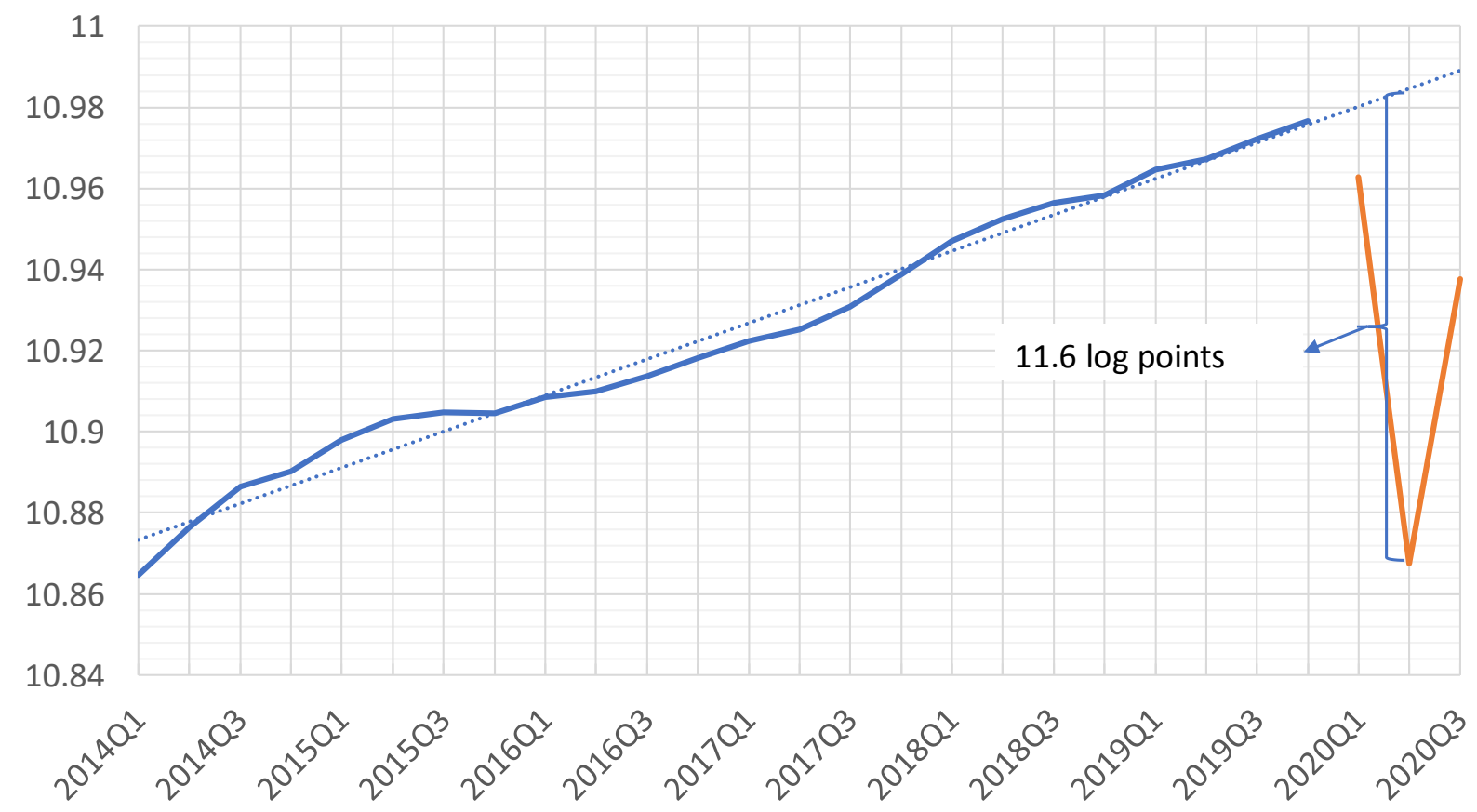

Note: The solid lines show real GDP per capita (from FRED) plotted in natural log units from 2014 Q1 to 2019 Q4 (solid blue line) and 2020 Q1 to 2020 Q3 (orange line). The dashed line shows a linear fit to the pre-pandemic data and its extrapolation to the postpandemic period. The maximal gap between the dashed and orange curves of 11.6 log points which occurs in 2020 Q2.

Allowing the capital structure of firms to include bonds as well as equity claims would magnify the stock price reaction to realized disasters. We do not seek to quantify the leverage effect here, but we doubt it is large enough to bring the model in line with the size of the stock market crash. Another potential explanation starts with the observation that traded equities are a claim on only part of the economy. On the whole, listed firms appear to be better positioned than other parts of the economy to weather the pandemic and to profit from pandemic-induced shifts in the structure of the economy. Thus, we do not see this line of explanation as promising.

\section{What Accounts for National Stock Prices During the Pandemic?}

\section{A. The Role of Pandemic Severity, Lockdown Stringency, and Economic Support}

Table 2 considers regression models that aim to account for national stock prices at a daily frequency during the period covered by Figures 4 and 5. (Table A.1 provides summary statistics for the variables.) We fit models to national data for 34 countries on trading days from 17 February to 21 May 2020. As we have seen, common global dynamics are a pronounced feature of stock prices and mobility during the sample period. ${ }^{11}$ Thus, we include common time

\footnotetext{
${ }^{11}$ Regressing national stock price deviations from 17 February to 21 May on a full set of day fixed effects yields an adjusted R-squared value of 0.85 . Analogous regressions yield an adjusted R-squared value of 0.85 for workplace mobility deviations, 0.94 for the stringency of market lockdown measures, and 0.24 for COVID-19 deaths per million persons.
} 
effects in columns (1) to (3), and we adopt the common correlated effects (CCE) estimator advocated by Pesaran (2006) in columns (4) to (6). The CCE specification includes cross-country averages as explanatory variables.

The results provide strong evidence that the stringency of own-country and global lockdown measures have large negative effects on national stock prices, conditional on (a) own and global pandemic severity, (b) own and global economic activity, and (c) own and global income support and debt relief policies. Consider the CCE specification in column (6). Estimated coefficients on the own-country and the global lockdown stringency indexes are negative and statistically significant at the 1 percent level. With respect to magnitudes, the -9.5 coefficient says a unit standard deviation increase of 30.9 in own-country lockdown stringency (see Table A.1) lowers national stock prices by 2.9 percentage points, conditional on other variables. The results also say a unit standard deviation rise in global lockdown stringency lowers national stock prices by 4.9 percentage points conditional on other variables. These are large effects.

Turning to the other explanatory variables, the estimated effects of own-country economic support policies differ in sign across specifications, and the implied effect magnitudes are modest in all cases. There is weak evidence that increases in the extent of global economic support policies raises national stock prices. According to Column (6), a unit standard deviation increase in global average economic support policies raises stock prices by 1.5 percentage point, conditional on the other variables.

There are two odd aspects of the results in Table 2. First, higher global average mobility is associated with lower stock prices in columns (4) to (6). Second, new COVID deaths per million are positively related to national stock prices, although the implied effects are modest in size. For example, using the estimates in Column (6), a unit standard deviation increase in the rate of own-country (global) new deaths is associated with a $0.31(0.12)$ percentage point increase in national stock prices.

New COVID deaths per capita capture the current death rate but not the slope of its trajectory. To characterize the trajectory, we follow Mazumder et al. (2020) and calculate the time it takes for accumulated cases to double, as measured by

$$
\text { Doubling Time }{ }_{c, t, l}=\frac{t-l}{\log _{2}\left(N_{c, t} / N_{c, t-l}\right)},
$$

where $N_{c, t}$ and $N_{c, t-l}$ are accumulated confirmed cases at times $t$ and $t-l$ for country $c$. Figure A.4 plots national doubling times at a daily frequency calculated over one-day (i.e. $l=1$ ), 3-day, and 7-day intervals. Those figures reveal great heterogeneity in doubling times across countries and within countries over time. We set $l=7$ for use in our regression models.

National stock prices rise with own-country doubling time and with the product of owncountry death rates and doubling time. Both results align with the idea that stock prices improve as pandemic severity diminishes. However, the signs are reversed for the coefficients on the global average doubling time and interaction variables. 
Table 2. Accounting for National Stock Market Movements During the Pandemic Panel Regressions, Daily Country-Level Data from 17 February to 21 May 2020

$W M D_{c, t}=$ Percent Workplace Mobility Deviation in Country $c$ on Trading Day $t$ $S M D_{c, t}=$ Percent Stock Price Deviation from February 17 in Country $c$ on Trading Day $t$ $\omega_{c}=$ Market capitalization share of country $c$ using data as of 31 December 2018

\begin{tabular}{|c|c|c|c|c|c|c|}
\hline & \multicolumn{6}{|c|}{ Dependent Variable: $100 \times S M D_{c, t}$} \\
\hline Explanatory Variables & $(1)$ & $(2)$ & (3) & $(4)$ & $(5)$ & (6) \\
\hline$W M D_{c, t}$ & $\begin{array}{c}0.8 \\
(1.4)\end{array}$ & $\begin{array}{c}1.7 \\
(1.3)\end{array}$ & $\begin{array}{l}2.2^{*} \\
(1.3)\end{array}$ & $\begin{array}{c}0.7 \\
(1.4)\end{array}$ & $\begin{array}{c}1.1 \\
(1.3)\end{array}$ & $\begin{array}{c}1.7 \\
(1.3)\end{array}$ \\
\hline Deaths per million $_{c, t}$ & $\begin{array}{c}2.3 \\
(4.6)\end{array}$ & $\begin{array}{l}8.0^{*} \\
(4.1)\end{array}$ & $\begin{array}{l}8.4^{*} \\
(4.0)\end{array}$ & $\begin{array}{c}2.6 \\
(4.6)\end{array}$ & $\begin{array}{l}8.2^{* *} \\
(4.1)\end{array}$ & $\begin{array}{l}9.0^{* *} \\
(4.0)\end{array}$ \\
\hline $\log \left(\right.$ Doubling Time $\left._{c, t}\right)$ & & $\begin{array}{r}27.2^{*} \\
(14.3) \\
\end{array}$ & $\begin{array}{l}35.9^{* *} \\
(14.2)\end{array}$ & & $\begin{array}{l}32.9^{* *} \\
(14.2)\end{array}$ & $\begin{array}{l}42.1^{* * * *} \\
(14.2)\end{array}$ \\
\hline $\begin{array}{l}\text { Deaths per million }_{c, t} \times \\
\log \left(\text { Doubling }_{\text {Tim }}{ }_{c, t}\right)\end{array}$ & & & $\begin{array}{c}-18.6^{* * *} \\
(3.4)\end{array}$ & & & $\begin{array}{c}-19.1^{* * *} \\
(3.4)\end{array}$ \\
\hline $\begin{array}{l}\text { Stringency } \\
\text { Index } \\
c, t\end{array}$ & $\begin{array}{c}-8.0^{* * * *} \\
(1.3)\end{array}$ & $\begin{array}{c}-8.9^{* * *} \\
(1.2)\end{array}$ & $\begin{array}{l}-8.4^{* * *} \\
(1.2)\end{array}$ & $\begin{array}{c}-8.3^{* * *} \\
(1.3)\end{array}$ & $\begin{array}{c}-10.2^{* * * *} \\
(1.2)\end{array}$ & $\begin{array}{l}-9.5^{* * *} \\
(1.2)\end{array}$ \\
\hline $\begin{array}{c}\text { Economic } \\
\text { Support Index }{ }_{c, t}\end{array}$ & $\begin{array}{l}-1.4^{*} \\
(0.7) \\
\end{array}$ & $\begin{array}{c}1.1 \\
(0.7) \\
\end{array}$ & $\begin{array}{c}0.9 \\
(0.7) \\
\end{array}$ & $\begin{array}{l}-1.1 \\
(0.7) \\
\end{array}$ & $\begin{array}{l}1.5^{*} \\
(0.7) \\
\end{array}$ & $\begin{array}{l}1.2^{*} \\
(0.7) \\
\end{array}$ \\
\hline$\sum_{c} \omega_{c} \times W M D_{c, t}$ & & & & $\begin{array}{c}-15.2^{* * *} \\
(3.9)\end{array}$ & $\begin{array}{c}-14.8^{* * * *} \\
(3.6)\end{array}$ & $\begin{array}{c}-19.6^{* * *} \\
(4.4)\end{array}$ \\
\hline 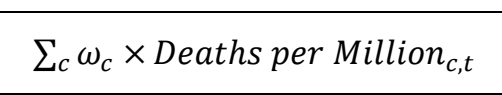 & & & & $\begin{array}{c}23.1^{*} \\
(13.0)\end{array}$ & $\begin{array}{c}10.1 \\
(12.0) \\
\end{array}$ & $\begin{array}{c}5.6 \\
(12.7) \\
\end{array}$ \\
\hline$\sum_{c} \omega_{c} \times \log ($ Doubling Time Tit, $)$ & & & & & $\begin{array}{l}-78.3^{* *} \\
(24.9)\end{array}$ & $\begin{array}{c}-128.9^{* * * *} \\
(37.1)\end{array}$ \\
\hline $\begin{array}{c}\sum_{c} \omega_{c} \times\left(\text { Deaths per million }_{c, t} \times\right. \\
\log \left(\text { Doubling }_{\text {Time }}, t, t\right)\end{array}$ & & & & & & $\begin{array}{l}27.1^{* * * *} \\
(10.5)\end{array}$ \\
\hline$\sum_{c} \omega_{c} \times$ Stringency Index $x_{c, t}$ & & & & $\begin{array}{c}-16.7^{* * *} \\
(4.0)\end{array}$ & $\begin{array}{c}-15.7^{* * * *} \\
(3.6)\end{array}$ & $\begin{array}{l}-20.1^{* * *} \\
(4.2)\end{array}$ \\
\hline$\sum_{c} \omega_{c} \times$ Economic Index $_{c, t}$ & & & & $\begin{array}{l}3.3^{*} \\
(1.9)\end{array}$ & $\begin{array}{l}3.4^{*} \\
(2.0)\end{array}$ & $\begin{array}{l}4.3^{* *} \\
(2.1)\end{array}$ \\
\hline$\sum_{c} \omega_{c} \times S M D_{c, t}$ & & & & $\begin{array}{c}87.0^{* * * *} \\
(2.9) \\
\end{array}$ & $\begin{array}{c}91.7^{* * * *} \\
(3.0) \\
\end{array}$ & $\begin{array}{l}91.5^{* * *} \\
(3.0)\end{array}$ \\
\hline Country Fixed Effect & YES & YES & YES & YES & YES & YES \\
\hline Time Fixed Effect & YES & YES & YES & $\mathrm{NO}$ & $\mathrm{NO}$ & NO \\
\hline $\begin{array}{c}N \\
\text { adj. } R^{2}\end{array}$ & $\begin{array}{l}2211 \\
0.96\end{array}$ & $\begin{array}{l}1950 \\
0.97\end{array}$ & $\begin{array}{l}1950 \\
0.97\end{array}$ & $\begin{array}{l}2211 \\
0.96\end{array}$ & $\begin{array}{l}1950 \\
0.97\end{array}$ & $\begin{array}{l}1950 \\
0.97\end{array}$ \\
\hline
\end{tabular}

Note: The sample covers trading days from 17 February to 21 May 2020 in 34 countries. When computing global means, we impute missing country-level values by linearly interpolating between trading days. The Stringency Index records the strictness of market lockdown measures, and the Economic Support Index captures the intensity of income support and debt relief policies. We calculate doubling times using 7-day intervals, and demean own-country and global $\log$ (Doubling Time) variables. The sample shrinks when including $\log$ (Doubling Time), because it is undefined before a country's first COVID-19 death and a lack of data for France. Columns (1)-(3) report OLS coefficient estimates with standard errors in parentheses. Columns (4)-(6) report estimates for Pesaran's (2006) Common Correlated Effects specification. ${ }^{*} p<.1,{ }^{* *} p<.05,{ }^{* * *} p<.01$. 


\section{B. Outlier Countries}

This section offers remarks on selected economies that exhibit highly distinctive, relatively favorable experiences with respect to workplace mobility, stock prices, or both. Figure 7 plots workplace mobility deviations against stock market deviations in panel (a) and stringency index values in panel (b) as of 30 March 2020, when the global stringency index first reaches 70. In the upper right corner of panel (a) are Taiwan, Singapore, South Korea, Japan and Sweden. These countries experienced relatively favorable stock price and workplace mobility deviations. All but South Korea also had comparatively low stringency index values. We note, however, that South Korea was slow to impose a hard lockdown. It took 60 days from the first confirmed case to reach a lockdown index value above 70, placing South Korea among the bottom three countries by this measure of lockdown speed, along with Thailand and Singapore. Sweden, Japan and Taiwan did not implement a hard lockdown within our sample period.

Figure 7. Scatterplot of Workplace Mobility Deviation vs. Stock Market Deviation/Stringency Index on 30 March 2020

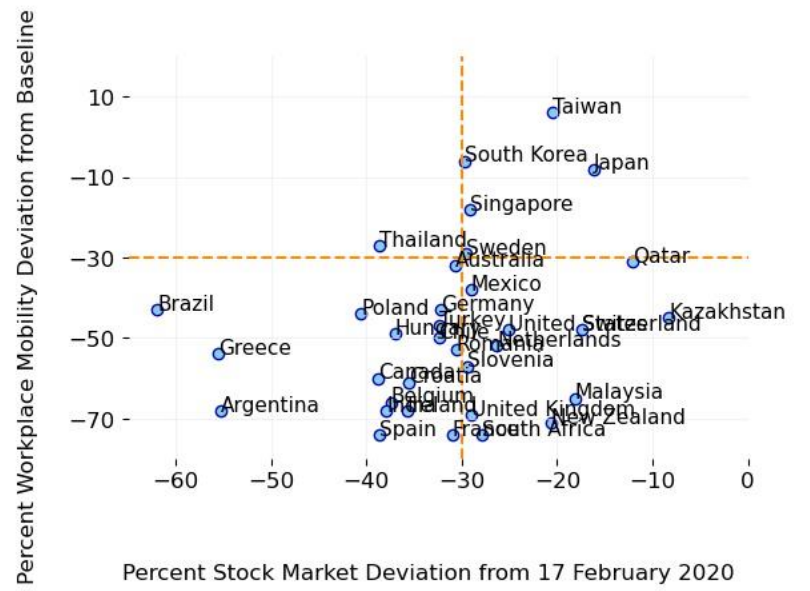

(a)

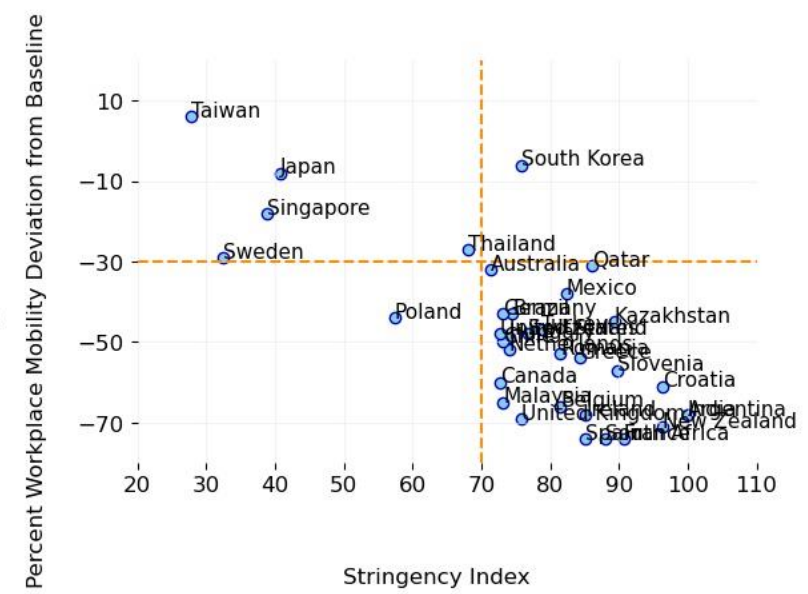

(b)

Note: We choose 30 March 2020 when the aggregated global stringency index first reaches 70, a hard lockdown by our definition.

Taiwan, Singapore, South Korea and Japan are East Asian economies that drew lessons from the 2003 SARS epidemic. Before the COVID-19 outbreak, they had established comprehensive laboratory and medical surveillance systems to cope with pandemics. Taiwan, in particular adopted many containment measures at impressive speed in response to COVID. According to Cheng et al. (2020), "At the early stage of the outbreak, the strategy in Taiwan had three pillars: real-time surveillance with rapid risk assessment, border control and quarantine, and laboratory capacity building."

Governments in South Korea and Singapore exploited access to mobile phone data of residents for contact tracing and virus containment. South Korea adopted an effective trace-testtreat policy. In these cases, fast government reactions, legal and technical infrastructures that supported rapid interventions, harsh penalties for violations of laws and regulations, and highquality health care systems served as crucial enabling factors (Park et al., 2020). According to 
Woo (2020), the later emergence of large infection clusters among Singapore's foreign workers overwhelmed hospital capacity, leading to high infection rates.

Japan is another country that successfully suppressed the initial spread of the disease. In addition to good governance and a strong health care system, the socially responsible and riskaware behavior of its citizens enabled Japan to contain infection rates while also limiting economic damage, according to Tashiro and Shaw (2020).

The Swedish response has been exceptional in its comparative leniency and reliance on individuals to act responsibly and adhere to public recommendations. As Hensvik and Skans (2020) write, "Sweden's restrictions have been relatively mild compared to other European countries. The measures primarily rely on voluntary compliance with recommendations from the Public Health Agency regarding social distancing." Trust in the political and administrative system is a key to the Swedish approach, according to Dahlberg et al. (2020).

\section{Additional Remarks on Related Literature}

Alan et al. (2020) find that the daily number of active COVID-19 cases and the curvature of the active-case trajectory help predict stock market volatilities in a cross section of countries. Larger caseloads (relative to population) bring greater volatilities, according to their analysis. They also find that stricter lockdown polices bring lower stock market volatilities, while more frequent expressions of negative sentiment in corporate earnings conference calls bring higher volatilities. Our study is complementary to theirs in two respects: first, in its focus on stock price levels rather than volatilities, and second, in considering the dynamic relation of stock prices to workplace mobility in addition to measures of pandemic severity.

Cox et al. (2020) find that fluctuations in effective risk aversion or sentiment are the major driver of stock market volatility from February to April of 2020, while the Federal Reserve played a lesser role. Based on a theoretical analysis, Caballero and Simsek (2020) argue that an overshooting of asset prices and a temporary disconnect between Wall Street and Main Street during the COVID-19 recession are features of an optimal monetary policy, because the central bank should deliberately boost asset prices to close the output gap as fast as possible.

Chen and Spence (2020) show that mobility-based proxies for economic activity align well with more standard measures of economic activity. They argue that fast policymaker response to COVID-19 outbreaks, coupled with strong detection and tracking abilities, enable a country to limit both infections and economic damage. Deb et al. (2020) estimate the effects of COVID containment measures on Nitrogen Dioxide emissions, flights, energy consumption, maritime trade, and mobility indices. They find that workplace closures and stay-at-home orders are effective in curbing infections (and more effective than other containment measures) but also involve large economic costs (larger than other measures). While they do not consider stock price behavior, we see their findings as broadly consistent with ours.

\section{The China Experience}

Thus far, we have said little about stock prices and economic activity in China. There are good reasons to separately examine the Chinese experience. First, the pandemic erupted first in China, when little was known about the SARS-COV-2 virus. Second, after initially suppressing 
information about the viral outbreak in Hubei province (Kynge et al., 2020, and Jacob, 2020), the Chinese government imposed aggressive containment measures. Third, as we will show, the dynamic between stock prices and economic activity played out differently in China than elsewhere, including other countries with relatively successful containment efforts.

\section{A. Sources of Data for China}

Our high-frequency proxy for economic activity in China relies on daily city-level data on residential commuting intensity from Baidu (2020),

$$
R C I_{c, t}=\frac{\text { residents traveling within city } c \text { on date } t}{\# \text { of residents in city } c}
$$

We obtain the daily city-level data from the Harvard Dataverse. To construct a national mobility measure, we compute the weighted-average $R C I_{c, t}$ values over 248 Chinese cities, using the number of residents in 2019 as weights. Consistent with Google's construction of workplace mobility, we use the median value from 1 to 10 January 2020 as the baseline.

Equity securities of publicly traded Chinese firms are listed on multiple exchanges and denominated in multiple currencies, as follows: A shares are listed on mainland exchanges, denominated in RMB, and traded by investors in mainland China. B shares are listed on mainland exchanges but denominated in foreign currencies. On the Shanghai Exchange, B shares trade in U.S. dollars. On the Shenzhen Exchange, B shares trade in Hong Kong dollars. H shares are listed on the Hong Kong Stock Exchange (HKEX), denominated in HKD, and traded by investors outside mainland China. Some Chinese companies list on multiple exchanges and in multiple currencies. Table 3 reports firm listing counts and market capitalization in various categories. Clearly, A shares dominate in terms of listing counts and market capitalization. Moreover, among A shares, firms that list only on mainland exchanges account for nearly fourfifths of market cap. We consider these "A-share only" firms when relating Chinese stock prices to our mobility measure for China. In other investigations below, we separately consider outcomes for the Shanghai Stock Exchange (SSE) and the HKEX.

Table 3. Number and Market Cap of Listed Chinese Firms

\begin{tabular}{|c|c|c|c|}
\hline Firm Type & $\begin{array}{c}\text { Number of } \\
\text { Firms }\end{array}$ & $\begin{array}{c}\text { Market Capitalization, } \\
\text { Trillions of RMB }\end{array}$ & $\begin{array}{c}\text { Market Cap \% of } \\
\text { Share Type }\end{array}$ \\
\hline \multicolumn{5}{|c|}{ A Shares } \\
\hline All Firms with A shares & 3740 & 59.49 & 100 \\
\hline Those without H shares & 3621 & 46.70 & 79 \\
\hline Those with H shares & 119 & 12.79 & 100 \\
\hline \multicolumn{5}{|c|}{ B Shares } \\
\hline All Firms with B shares & 92 & 0.63 & 89 \\
\hline Those without A hares & 16 & 0.07 & 11 \\
\hline Those with A shares & 76 & 0.56 & 17 \\
\hline \multicolumn{5}{|l|}{ H Shares } \\
\hline All Firms with H shares & 258 & 5.09 & 83 \\
\hline Those without A shares & 139 & 0.83 & \\
\hline Those with A shares & 119 & 4.26 & \\
\hline
\end{tabular}


Note: We select firms that trade actively from 2 January to 31 July 2020. The market capitalization value is based on values as of 7 August 2020. Data for A and B shares are from CSMAR, accessed on 7 August 2020. Data for $\mathrm{H}$ shares are downloaded from Yahoo Finance. We use 1HKD $=0.9 \mathrm{RMB}$ to convert currencies. The total Hong Kong market cap is 38 trillion RMB, and H shares account for $13.5 \%$.

\section{B. Stock Prices and Mobility in China}

Figure 8 plots the evolution of the China mobility measure as a percent deviation from baseline. Mobility fell sharply after 20 January, bottomed out on 15 February and then recovered gradually, returning to baseline by late April. The fall in mobility on 10 April (Friday, nonholiday) is likely due to new COVID-19 cases among travelers from outside China. Having heard this news, Chinese residents responded with caution about visiting public places.

Figure 9 presents the time path of stock price and mobility deviations in China. Unlike other countries, stock prices do not precede declining mobility in China. Instead, the figure shows large, broadly coincident declines in stock prices and mobility from 15 January to 3 February. Mobility fell roughly 60 percent over this period, and stock prices fell nearly 20 percent. The exact timing of stock price developments is obscured by the Spring Festival closure of mainland exchanges, which the government extended as part of its policy response to the pandemic. After last trading on 24 January, mainland exchanges re-opened on 3 February, with stock prices down 11 percentage points. During the market shutdown, mobility fell 34 percentage points. On 4 February, the second day after the stringency index surpassed 70, stock prices began to climb as mobility fell another 6 points. From 6 February to 4 March, mobility rose 36 points and stock prices rose 11 points. From 5 March to 30 April, mobility rose another 30 points and returned to baseline, while stock prices increased by 9 points.

Figure 8. China Mobility, Percent Deviation from the Baseline

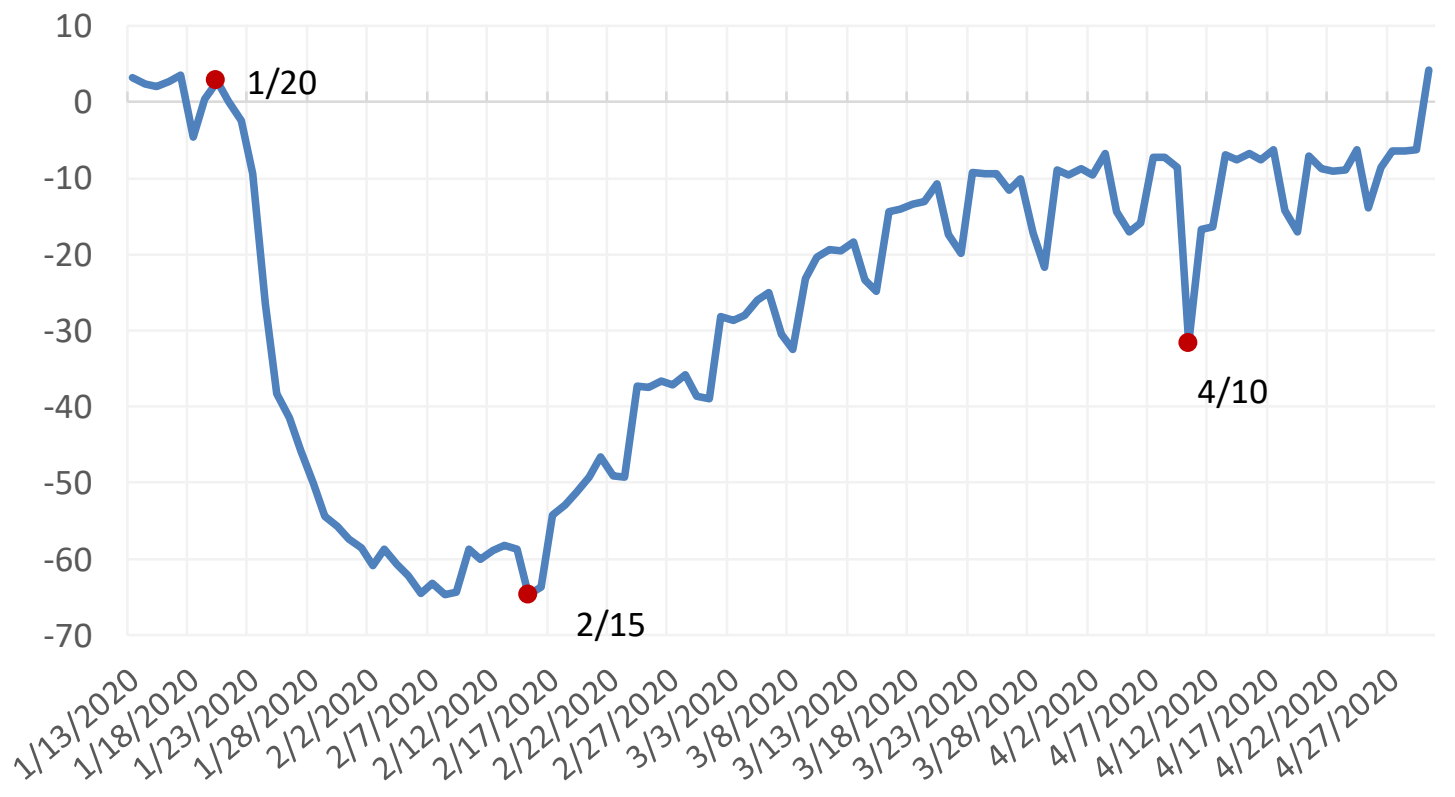

Note: China mobility is defined as residents traveling at city $c$ on date $t$ over the number of residents at date $t$. In calculating the weighted average of China mobility, we use each city's number of residents in 2019 as the weight. The daily China mobility index for each city is recorded by Baidu, and we obtain the data from Harvard Dataverse, accessed on 15 August. The Baidu mobility data stopped updating since 2 May. We choose the median value of the mobility from 1 to 10 January 2020 as the baseline. 
Figure 9. Time Path of China Stock Prices and Mobility from 13 January to 30 April 2020

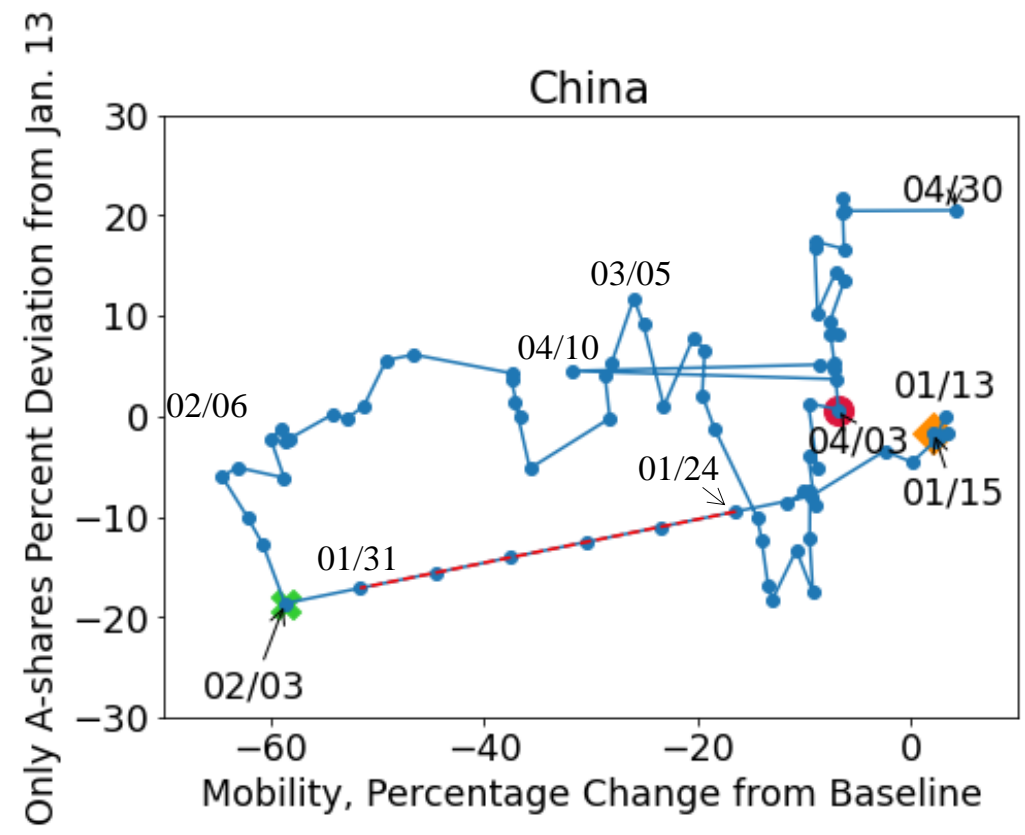

Note: Stock prices are from the CSMAR dataset (China analog to WRDS). An orange diamond marks the first confirmed COVID-19 death, a green cross marks the first date with stringency index value of 70 or more, and a red dot marks the date on which the stringency index first drops below 70 . We linearly interpolate stock prices from 24 January to 3 February, given that mainland China stock markets were closed from 25 January to 2 February, inclusive.

\section{Comparison of Chinese and American Stock Markets}

Unlike the American stock market, the Chinese stock market attracts millions of domestic retail investors. This makes China's stock market less tied to the global financial system, but more sensitive to governmental influences ( $\mathrm{Yu}$ and Ping, 2020). Figure 10 compares cumulative $\log$ returns on Chinese and American stocks during the first four months of 2020, and Figures 11 and 12 compare realized and implied stock market volatility over the same period. All three charts exhibit the same pattern: the coronavirus pandemic had the largest impact on the S\&P 500, a relatively modest impact on the SSE, and an intermediate effect on the Hang Seng.

Chinese authorities closed mainland stock exchanges for an extra three working days during the 2020 Spring Festival break. Accordingly, the SSE announced on 27 January 2020 that the it would reopen on 3 February instead of 31 January. ${ }^{12}$ As a result, mainland markets did not register the impact of the mounting coronavirus cases during the period from 25 January through 2 February, whereas U.S. markets quickly reflected new developments. The extended market closure may have contributed to the lower volatility Chinese stock markets even after the closure period itself.

Table 4 classifies the contemporaneously perceived reasons for daily stock market jumps based on explanations offered in next-day newspaper accounts, following the approach of Baker

${ }^{12}$ http://www.sse.com.cn/aboutus/mediacenter/hotandd/c/c 20200202 4991648.shtml 
et al. (2020b). They examine next-day newspaper explanations to classify and characterize each daily move in the U.S. stock market greater than 2.5 percent, up or down, from 1900 to the present. Specifically, they read the lead article about each jump in next-day newspapers (or the same evening in the internet era) to classify the journalist's explanation into one of 16 categories, which include Macroeconomic News and Outlook, Government Spending, Monetary Policy, Unknown or No Explanation Offered, and Other - Specify. ${ }^{13}$ Baker et al. (2020a) extended the approach to investigate the specific role of pandemics and infectious diseases.

Panel $\mathrm{C}$ in Table 4 underscores the unprecedented impact of the COVID-19 pandemic on the U.S. stock market. In the period before 24 February 2020 - spanning 120 years and more than 1,100 jumps - next-day journalistic accounts attributed not a single daily stock market jump to infectious disease outbreaks or policy responses to such outbreaks. Perhaps surprisingly, even the Spanish Flu fails to register in next-day journalistic explanations for large daily stock market moves. There were 23 daily stock market jumps from March 1918 to June 2020, which spans the three major waves of the Spanish Flu. Next-day accounts in the Wall Street Journal attributed none of them to the Spanish Flu. Data since late February 2020 tell a remarkably different story. From February 24 through the end of April, there were 27 U.S. stock market jumps. Next-day newspaper accounts attribute 23 or 24 of them (depending on newspaper) to news about COVID19 developments and policy responses to the pandemic.

We take the same approach to the Shanghai Stock Exchange and the Hang Seng from 26 December 1990 to 30 April 2020. In doing so, we tap financially-oriented mainland Chinese newspapers for SSE jumps and the South China Morning Post for Hang Seng jumps. Before COVID-19, newspapers attribute zero jumps (out of hundreds) to news about infectious diseases. From 2 January to 30 April 2020, Chinese newspapers attribute all 6 daily stock market moves greater than $|3 \%|$ on the SSE and all 8 daily moves greater than $|3.8 \%|$ on the Hang Seng to the economic fallout of the pandemic or policy responses to the pandemic. ${ }^{14}$ These results closely parallel the U.S. results. However, the incidence of large daily stock moves during the coronavirus period is several times greater for the U.S. market than for the Chinese stock markets, in line with the extremely high volatility of the U.S. market during this period.

To summarize, our comparison of Chinese and American stock markets during the coronavirus period uncovers four findings. First, and not surprisingly, stock prices fell less steeply in China. Second, implied and realized stock market volatility rose much more sharply in the United States than in China, particularly mainland China. Greater equity market volatility in the U.S. than in China from late February 2020 (and through late April) is a reversal of the usual relationship. Related, the incidence of large daily stock market moves is several times greater in the United States in the wake of the coronavirus. Third, next-day newspaper accounts confirm the dominant role of pandemic-related news in driving market volatility in both countries after the onset of the pandemic. Finally, the powerful effects of pandemic-related news on stock markets is without precedent since at least 1990 in China and since 1900 in the United States.

\footnotetext{
${ }^{13}$ The coding guide in Baker, Bloom, Davis, and Sammon (2018) describes the approach in detail.

${ }^{14}$ Following Baker et al. (2020b), we set higher jump thresholds for the SSE and the Hang Seng to adjust for their greater baseline volatility levels.
} 
Figure 10. Cumulative Log Returns on American and Chinese Stocks, 2 January to 29 April 2020

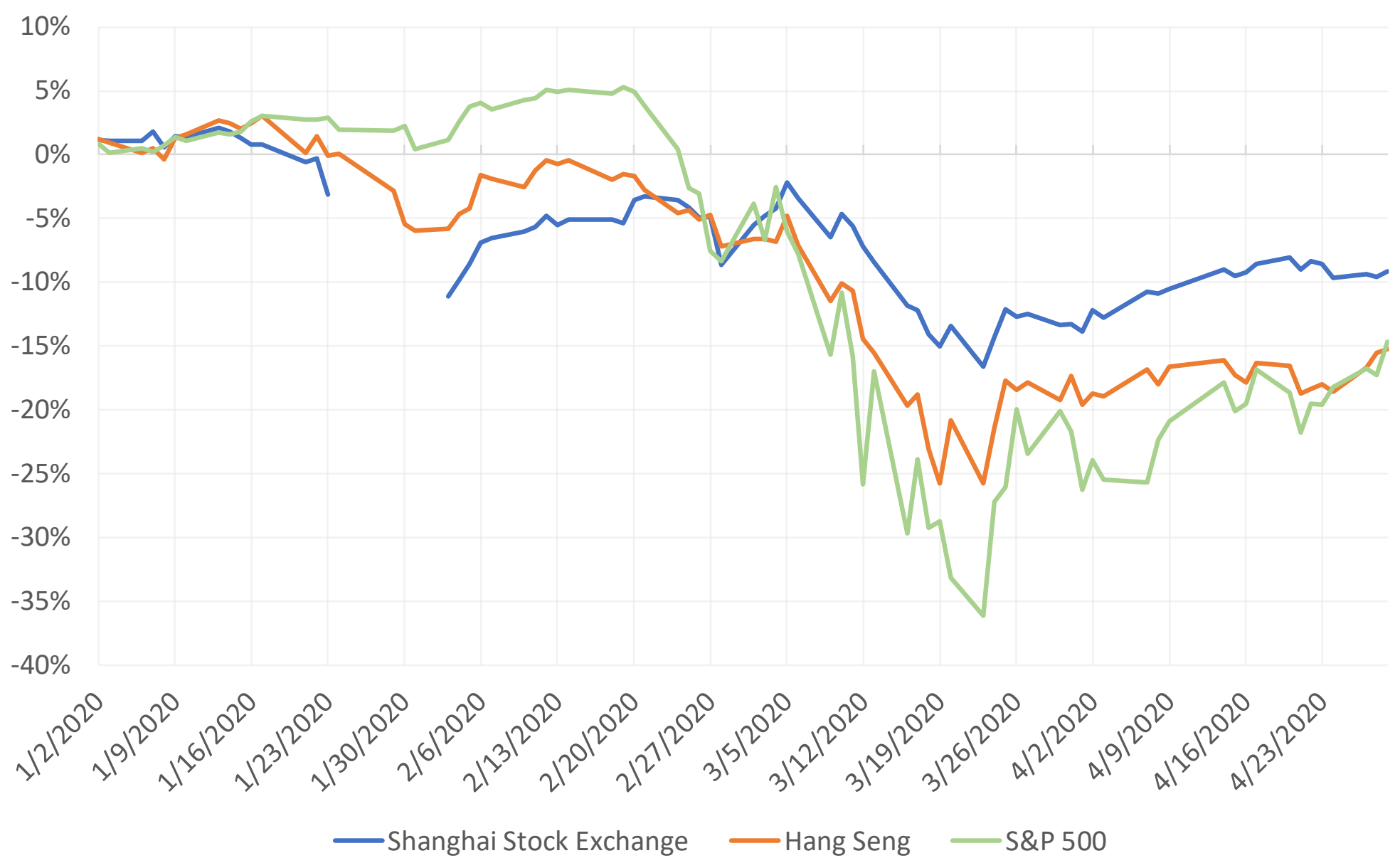

Note: The figure plots cumulative log changes from 31 December 2019 for the indicated stock market indexes, using daily closing values from Yahoo Finance, downloaded on 4 May 2020. The break in blue line indicates the Spring Festival market closure in Shanghai Stock Exchange, from January 24 (Friday) to February 2 (Sunday). 
Figure 11. Realized Return Volatility Over Past 10 Trading Days, American and Chinese Stocks, 31 December 2019 to 29 April 2020

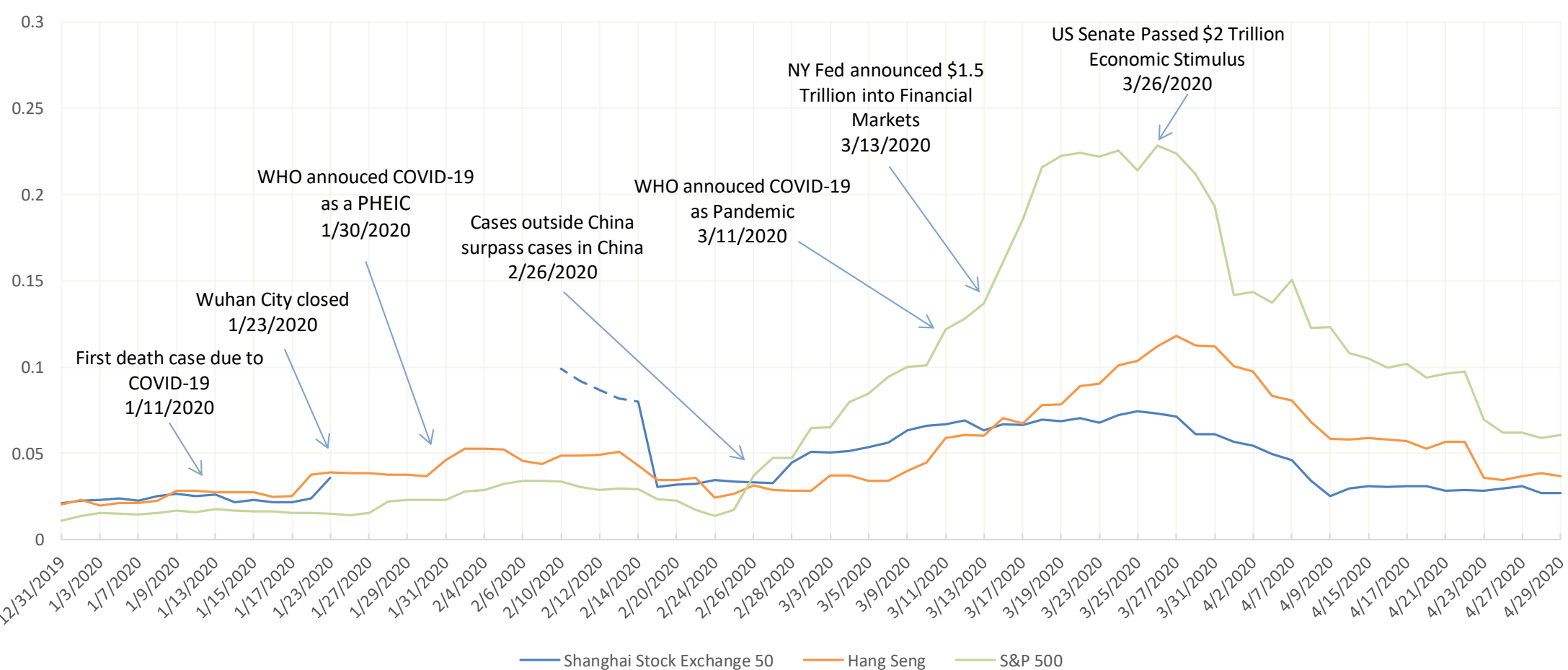

Notes: We measure realized volatility as the square root of the sum of squared returns over the past 10 trading days, calculating returns as log changes in closing-price index values. We linearly interpolate over weekends and other short market closures. The break in the series for the Shanghai Stock Index reflects an extended market closure for the Chinese Spring Festival and the coronavirus pandemic, which we handle as follows: (1) Let $\mathrm{j}=0,1,2, \ldots, N^{c}$ index days, where $\mathrm{j}=1$ is the first closure day and $\mathrm{j}=N^{c}$ the last closure day. (2) Treat the volatility data as missing for $\mathrm{j}=1$ to $N^{c}+5$, and do not interpolate across these missing days. (3) For $\mathrm{j}=N^{c}+\mathrm{k}$ for $\mathrm{k}=6$ to 10 , compute past volatility by summing the squared returns over the past k-1 days (i.e., inclusive of the change from $\mathrm{k}-1$ to $\mathrm{k}$ ) and multiplying the sum by (10/(k-1)). This multiplication factor adjusts for the shorter volatility window. Then we take the square root. (4) When plotting the realized volatility data for the interval from $\mathrm{j}=N^{c}+\mathrm{k}$ for $\mathrm{k}=6$ to 10 , we use a dashed line. 
Figure 12. Implied Volatilities, American and Chinese Stock Markets, 31 December 2019 to 30 April 2020

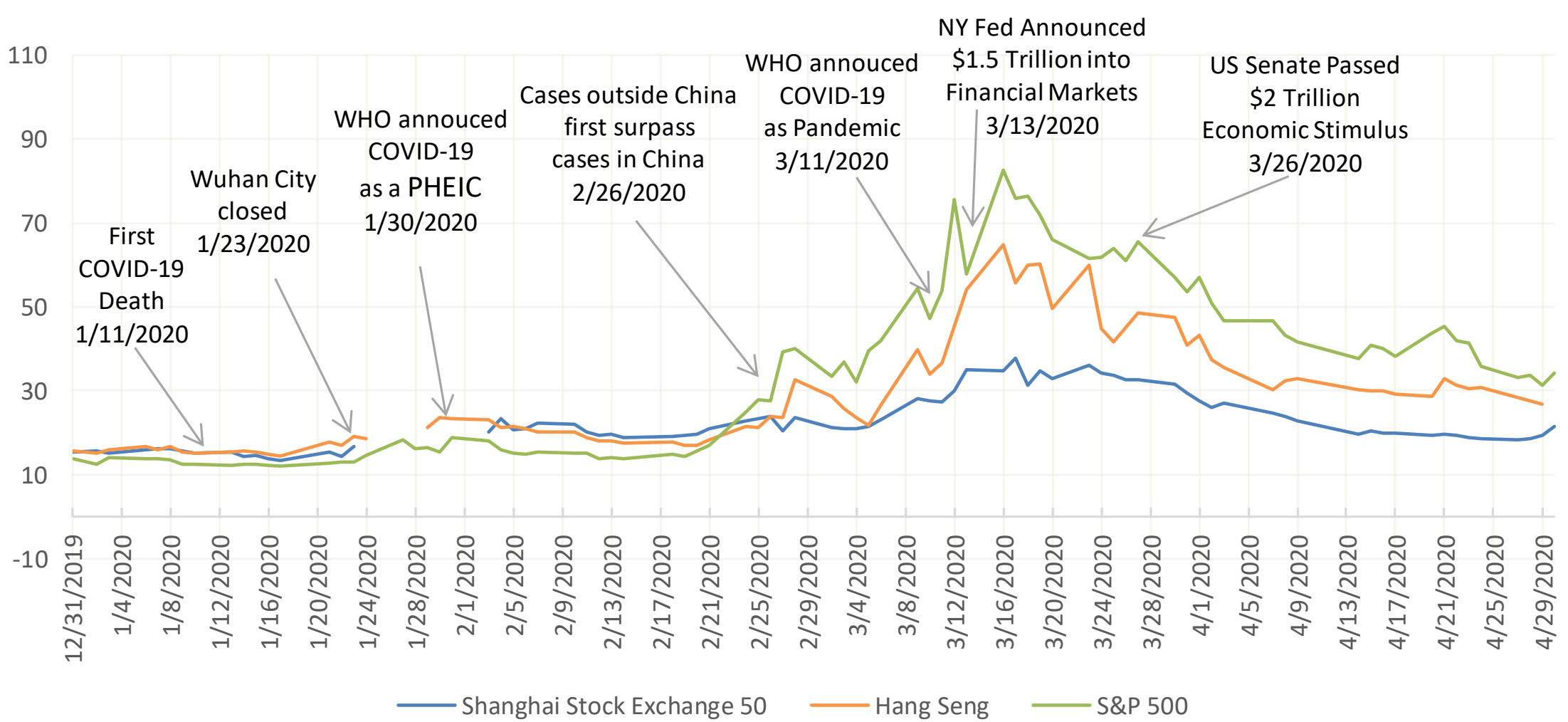

Note: Data for the Hang Seng Volatility Index (HSI Volatility Index) and the VIX (S\&P 500) are from Yahoo Finance, downloaded on 4 May 2020. We calculated an implied volatility index for the Shanghai Stock Exchange 50 as explained in Appendix B, following the same approach as CBOE (2019) uses to calculate the VIX. 
Table 4. Large Daily Moves in Chinese Stock Markets, Classifications Based on Next-Day Newspaper Accounts in Leading Chinese Newspapers

A. Shanghai Stock Exchange

\begin{tabular}{|c|c|c|c|c|}
\hline Time Period & $\begin{array}{c}\text { Jump } \\
\text { Size }\end{array}$ & $\begin{array}{c}\text { Number of } \\
\text { Daily Stock } \\
\text { Market Jumps }\end{array}$ & $\begin{array}{c}\text { \# Attributed to } \\
\text { Economic Fallout } \\
\text { of Pandemics }\end{array}$ & $\begin{array}{c}\text { \# Attributed to } \\
\text { Policy Responses } \\
\text { to Pandemics }\end{array}$ \\
\hline $\begin{array}{c}\text { 26 December 1990 } \\
\text { 31 December 2019 }\end{array}$ & $\geq|4 \%|$ & 384 & 0 & 0 \\
\hline $\begin{array}{c}\text { 2 January 2020 } \\
\text { to 30 April 2020 }\end{array}$ & $\begin{array}{c}\geq|4 \%| \\
<|4 \%|\end{array}$ & 1 & 1 & 0 \\
\cline { 2 - 5 } & 5 & 4 & 1 \\
\hline
\end{tabular}

\section{B. Hang Seng}

\begin{tabular}{|c|c|c|c|c|}
\hline Time Period & $\begin{array}{c}\text { Jump } \\
\text { Size }\end{array}$ & $\begin{array}{c}\text { Number of } \\
\text { Daily Stock } \\
\text { Market Jumps }\end{array}$ & $\begin{array}{c}\text { \# Attributed to } \\
\text { Economic Fallout } \\
\text { of Pandemics }\end{array}$ & $\begin{array}{c}\text { \# Attributed to } \\
\text { Policy Responses } \\
\text { to Pandemics }\end{array}$ \\
\hline $\begin{array}{c}\text { 26 December 1990 } \\
\text { 31 December 2019 }\end{array}$ & $\geq|3.8 \%|$ & 213 & 0 & 0 \\
\hline 2 January 2020 \\
to 30 April 2020
\end{tabular}$\quad$\begin{tabular}{c}
$\geq|3.8 \%|$ \\
\cline { 2 - 5 }
\end{tabular}

C. $S \& P 500$ (Reproduced from Baker et al. 2020a)

\begin{tabular}{|c|c|c|c|}
\hline & $\begin{array}{c}\text { Number of Daily U.S. } \\
\text { Stock Market Jumps } \\
\text { Greater than } 2.5 \%\end{array}$ & $\begin{array}{c}\text { Number Attributed } \\
\text { to Economic Fallout } \\
\text { of Pandemics }\end{array}$ & $\begin{array}{c}\text { Number Attributed to } \\
\text { Policy responses to } \\
\text { Pandemics }\end{array}$ \\
\hline $\begin{array}{c}\text { 2 January 1900 to } \\
\text { 21 February 2020 }\end{array}$ & 1,116 & 0 & 0 \\
\hline $\begin{array}{c}\text { 26 December 1990 } \\
\text { to 31 December 2019 }\end{array}$ & 254 & 0 & 0 \\
\hline $\begin{array}{c}\text { 2 January 2020 to } \\
\text { 23 February 2020 }\end{array}$ & 0 & 0 & 0 \\
\hline $\begin{array}{c}\text { 24 February 2020 to } \\
\text { 30 April 2020 }\end{array}$ & 27 & 13.4 & 10.4 \\
\hline
\end{tabular}

Notes to Panel A: We consult next-day accounts of large daily stock market jumps in four official Chinese newspapers: Security Times (证券时报), Security Daily (证券日报), Shanghai Security News (上海证券报), and China Security Journal (中国证券报). These four major securities newspapers are the most authoritative and influential securities newspapers in China. They are the first to report the securities market information and government policies and thus are important sources of market information for investors. We classify the reason for the jumps based on the explanation offered in the next-day account, following the approach in Baker et al. (2020b). At least one paper contains a next-day article about each large daily stock market jump, as defined in the table. When multiple papers contain a next-day article about a given jump, they always agree as to the reason for the jump. On 3 February 2020, the first trading day after the Chinese Spring Festival, the Shanghai Stock Index fell 7.72\%. On the next day, all four 
newspapers discussed the Shanghai Stock Market crash due to economic fallout of COVID-19 pandemics. The five dates with market jump greater than -or equal to $|3 \%|$ and less than $|4 \%|$ are: 28 February 2020 (-3.71\%), 2 March 2020 (3.15\%), 9 March 2020 (-3.01\%), 16 March 2020 ($3.40 \%)$, and 23 March $2020(-3.11 \%)$. The newspapers attributed the drops on 9, 19 and 23 March to the impact of Pandemics. On 24 March, Shanghai Securities News said that the Pandemics caused a shrinked external demand from Europe and the U.S., who are China's first and second biggest trade partners. The A-share stock slipped in response to this demand shock. On 17 March, Security Times reported that major central banks' monetary policy surprised the market and caused the market to drop. On 10 March, Securities Daily attributed the A-share stock falls to reduced demand in overseas market due to panic on oil price and coronavirus. On 3 March, China Securities Journal ascribed the market increase to the improved situation in China compared to the rest of the world. On 29 February, according to Security Times, the A-share stock dropped along with the overseas stock markets which were affected by rising new COVID cases around the world.

Notes to panel B: To examine what drives HK stock market's reaction, we consult next-day accounts of large daily stock market jumps in South China Morning Post. Following the same methodology in Panel A, we classify the reason for the market jumps. The seven dates with market jump greater than $|3.8 \%|$ in 2020 are: 9 March (-4.23\%), 16 March (-4.03\%), 18 March (4.18\%), 20 March (5.05\%), 23 March (-4.86\%), 24 March (4.46\%) and 25 March (3.81\%). The newspapers attributed the drops on 9, 16, 18, 20 and 23 March to the impact of the pandemics, while policy stimulation boosted the market on 24 and 25 March.

Notes to panel C: Based on the results in Baker et al. (2020a, 2020b), they consider all daily jumps in the U.S. stock market greater than $2.5 \%$, up or down, since 1900 . They classify the reason for each jump into 16 categories based on human readings of next-day (or same-evening) accounts in the Wall Street Journal (and New York Times in 2020). Fractional counts arise when newspapers differ in their jump attribution or human readers differ in their classification of the attribution, e.g. 12 and 16 March.

\section{Concluding Remarks}

The early stages of the COVID-19 pandemic drove a spectacular rout in stock markets. Within the space of a few weeks, value-weighted share prices fell 20 to 50 percent in countries around the world. The stock market implosions preceded short-term collapses in economic activity by two to three weeks in all but 3 of the 35 countries in our sample: South Korea saw only a modest activity drop in the wake of the pandemic, and Taiwan experienced none at all. China, the first country hit by the pandemic, experienced a simultaneous collapse in stock prices and economic activity.

Conditional on global developments, national stock prices foreshadowed the timing and severity of own-country collapses in economic activity in the wake of the pandemic. Thus, it is fair to say that stock prices exhibited strong predictive content for the collapses in economic activity that followed on the heels of the pandemic and policy responses to it. That said, we also show that the global and U.S. stock market crashes in reaction to the pandemic are many times larger than implied by a standard asset-pricing model, given plausible values for the magnitude of the COVID-19 output disaster. 
Regarding policy, our evidence is broadly supportive of two propositions. First, more aggressive lockdown measures brought larger drops in national stock prices, conditional on pandemic severity, economic support policies, and then-current activity levels as measured by workplace mobility. The negative responses of stock prices to own-country and global-average lockdown stringency are large. Presumably, larger stock price drops reflected bigger downward revisions in the economic outlook, suggesting that investors saw harsher lockdowns as worse news about future economic performance. Second, countries that moved quickly to contain the spread of the virus - with or without particularly aggressive market lockdown measures enjoyed higher stock prices and better near-term economic performance. In short, relatively successful policy responses involved rapid implementation of virus containment efforts but not necessarily strict lockdowns on economic and social activity.

We have not delved very deeply into the factors that enabled some countries to rapidly implement an effective set of containment measures. Still, our discussion of outlier countries points to several elements that appear to have played a positive role in this regard: encounters with major epidemics in the recent past (e.g., SARS in East Asia), the technical infrastructure needed to rapidly implement an effective test-trace-quarantine regime, a governance system that allowed for a rapid official response, an effective health-care system, and governments that either enjoyed the trust and cooperation of their citizens or had the means and will to compel compliance. It is perhaps understandable that many countries failed to create the infrastructure to implement an effective test-trace-quarantine system in advance of the COVID-19 pandemic. That many rich countries have been so slow to develop and deploy effective test-trace-quarantine systems points to a major role for political and institutional forces, rather than technical ones, as important impediments to more effective policy responses to the pandemic. 


\section{References}

Alan, Nazli Sila, Robert F. Engle, and Ahmet K. Karagozoglu, 2020. "Multi-regime Forecasting Model for the Impact of COVID-19 Pandemic on Volatility in Global Equity Markets," Available at SSRN 3646520; 15 June.

Albuquerque, Rui A., Yrjo J. Koskinen, Shuai Yang, and Chendi Zhang, 2020. "Resiliency of Environmental and Social Stocks: An Analysis of the Exogenous COVID-19 Market Crash," The Review of Corporate Finance Studies, 7 July.

Alfaro, Laura, Anusha Chari, Andrew Greenland, and Peter K. Schott, 2020. "Aggregate and Firm-Level Stock Returns During Pandemics, in Real Time," NBER Working Paper 26950; Apr 2.

Altig, Dave, Scott Baker, Jose Maria Barrero, Nick Bloom, Phil Bunn, Scarlet Chen, Steven J. Davis, Julia Leather, Brent Meyer, Emil Mihaylov, Paul Mizen, Nick Parker, Thomas Renault, Pawel Smietanka and Greg Thwaites, 2020. "Economic Uncertainty Before and During the COVID-19 Pandemic," Journal of Public Economics, in press.

Amstad, Marlen, Giulio Cornelli, Leonard Gambacorta and Dora Xia, 2020. 'Investors' Risk Attitudes in the Pandemic and the Stock Market: New Evidence Based on Internet Searches," BIS Bulletin 25, 26 June.

Baidu, China Data Lab, 2020, "Baidu Mobility Data", Harvard Dataverse, V16, link

Baker, Scott, Nicholas Bloom and Steven J. Davis, 2016. "Measuring Economic Policy Uncertainty," Quarterly Journal of Economics, 131(4), pp. 1593-1636.

Baker, Scott R., Nick Bloom, Steven J. Davis, Kyle Kost, Marco Sammon and Tasaneeya Viratyosin, 2020a. "The Unprecedented Stock Market Reaction to COVID-19," Review of Asset Pricing Studies, in press.

Baker, Scott, Nicholas Bloom, Steven J. Davis and Marco Sammon, 2018. "Coding Large Daily Financial Market Moves: Data Construction Guide". Available at https://stockmarketjumps.com/files/coding_guide_pdf.pdf.

Baker, Scott R., Nick Bloom, Steven J. Davis and Marco Sammon, 2020b. "What Triggers Stock Market Jumps?" working paper.

Barro, R.J., 2006. "Rare disasters and asset markets in the twentieth century". The Quarterly Journal of Economics, 121(3), pp.823-866.

Byung Mook Weon, 2020. "Doubling time tells how effective Covid-19 prevention works." March 30

Caballero, Ricardo J., and Alp Simsek. "A Model of Asset Price Spirals and Aggregate Demand Amplification of a 'Covid-19' Shock”. No. w27044. National Bureau of Economic Research, 2020.

Chen, Long and Michael Spence, 2020. "Five Lessons from Tracking the Global Pandemic Economy," VoxEU CEPR Policy Portal, 17 July.

Cheng, Hao-Yuan, Shu-Ying Li, and Chin-Hui Yang. "Initial rapid and proactive response for the COVID-19 outbreak-Taiwan's experience." Journal of the Formosan Medical Association 119, no. 4 (2020): 771.

Chicago Board of Options Exchange (CBOE), 2019. "White Paper: Cboe Volatility Index," available here.

Cox, J., Greenwald, D.L. and Ludvigson, S.C., 2020. "What Explains the COVID-19 Stock Market?” NBER Working Paper 27784. 
Dahlberg, Matz, Per-Anders Edin, Erik Grönqvist, Johan Lyhagen, John Östh, Alexey Siretskiy, and Marina Toger. "Effects of the covid-19 pandemic on population mobility under mild policies: Causal evidence from Sweden.” arXiv preprint arXiv:2004.09087 (2020).

Davis, Steven J., Stephen Hansen and Cristhian Seminario, 2020. "Firm-Level Risk Exposures and Stock Price Reactions to COVID-19," NBER Working Paper 27867.

Deb, Pragyan, Davide Furceri, Jonathan Ostry, and Nour Tawk, 2020. "The Effects of Containment Measures on the COVID-19 Pandemic," Covid Economics: Vetted and Real-Time Papers 19: 53-86.

Ding, Wenzhi, Ross Levine, Chen Lin and Wensi Xie, 2020. "Corporate Immunity to the COVID-19 Pandemic,” NBER Working Paper 27055.

Ferguson, Niall, 2020. "1918, 1957, 2020: Big Pandemics and their Economic, Social and Political Consequences," working paper, 20 May.

Gabaix, Xavier, 2012. "Variable rare disasters: An exactly solved framework for ten puzzles in macro-finance," Quarterly journal of economics, 127(2), 645-700.

Giglio, Stefano, Matteo Maggiori, Johannes Stroebel and Stephen Utkus, 2020. "The Joint Dynamics of Investor Beliefs and Trading During the COVID-19 Crash," September.

Google, 2020. COVID-19 Community Mobility Reports at www.google.com/covid19/mobility/.

Gormsen, Niels J. and Ralph Koijen, 2020. "Coronavirus: Impact on Stock Prices and Growth Expectations," Review of Asset Pricing Studies, 10(4), 574-597.

Hale, Thomas, Sam Webster, Anna Petherick, Toby Phillips, and Beatriz Kira, 2020. "Oxford COVID-19 Government Response Tracker", Blavatnik School of Government, at www.bsg.ox.ac.uk/research/research-projects/coronavirus-government-response-tracker.

Hassan, Tarek A., Stephan Hollander, Laurence van Lent and Ahmed Tahoun, 2020. "FirmLevel Exposure to Epidemic Diseases: COVID-19, SARS, and H1N1," NBER Working Paper 26971.

Hensvik, Lena, and O. Skans. "COVID-19 Crisis Response Monitoring: Sweden.” (2020).

Jacob, Jabin T., 2020. “'To Tell China's Story Well': China's International Messaging during the COVID-19," China Report, 56, no. 3 (July), 374-392.

Johns Hopkins University, 2020. "COVID-19 Data Repository", Center for Systems Science and Engineering, at https://github.com/CSSEGISandData/COVID-19/tree/master/csse_ covid 19 data.

Kynge, James, Sun Yu and Tom Hancock, 2020. "Coronavirus: The Cost of China's Public Health Cover-Up," Financial Times, 6 February 2020.

Landier, Augustin and David Thesmar, 2020. "Earnings Expectations during the COVID-19 Crisis," Review of Asset Pricing Studies, 10(4), 598-617.

Lucas, Robert E., 1978. "Asset Prices in an Exchange Economy," Econometrica, 96, 1429-1445.

Mazumder, A., M. Arora, M. S. Sra, A. Gupta, P. Behera, M. Gupta, M. Agarwal et al., 2020. "Geographical variation in case fatality rate and doubling time during the COVID-19 pandemic.” Epidemiology \& Infection 148.

Mehra, Rajnish and Edward Prescott, 1985. "The Equity Premium: A Puzzle,” Journal of Monetary Economics, 15, 145-161.

Pagano, Marco, Christian Wagner and Joseph Zechner, 2020. "Disaster Resilience and Asset Prices," arXiv preprint arXiv:2005.08929, 22 May.

Papanikolaou, Dimitris and Lawrence D.W. Schmidt, 2020. "Working Remotely and the SupplySide Impact of COVID-19," NBER Working Paper 27330.

Park, Sangchul, Gina Jeehyun Choi, and Haksoo Ko. "Information technology-based tracing strategy in response to COVID-19 in South Korea-privacy controversies." Jama (2020). 
Pesaran, Hashem, 2006. "Estimation and Inference in Large Heterogeneous Panels with a Multifactor Error Structure," Econometrica, 74(4), 967-1012; July.

Ramelli, Stefano and Alexander F. Wagner, 2020. "Feverish Stock Price Reactions to COVID19," Swiss Finance Institute Research Paper No. 20-12, 21 April.

Rietz, T.A., 1988. "The equity risk premium a solution.” Journal of Monetary Economics, 22(1), 117-131.

Shiller J. Robert, 2020. "Understanding the Pandemic Stock Market," Project Syndicate, 7 July.

Tashiro Ai and Rajib Shaw, 2020. "COVID-19 Pandemic Response in Japan: What Is behind the Initial Flattening of the Curve?" Sustainability 12(13), 5250; June 28

Velde, Francois, 2020. "What Happened to the US Economy During the 1918 Influenza Pandemic? A View Through High-Frequency Data," Federal Reserve Bank of Chicago Working Paper 2020-11, 17 April.

Wachter, Jessica, 2013. “Can Time-Varying Risk of Rare Disasters Explain Aggregate Stock Market Volatility?” Journal of Finance, 68(3), 987-1035.

Woo, J.J., 2020. "Policy capacity and Singapore's response to the COVID-19 pandemic", Policy and Society, 39(3), 345-362, June 18.

World Health Organization, 2005. "Strengthening Health Security by Implementing the International Health Regulations," https://www.who.int/ihr/procedures/pheic/en/\#.

Yu, Xie and Chong Koh Ping, 2020. “'It Is All About Faith’: Eager Small Investors Buoy China Stocks in Market Maelstrom”, Wall Street Journal, 26 March. 


\section{Online Appendix A. Supplementary Material for Sections 1, 2 and 3}

Figure A.1. Workplace Mobility Deviation of Selected Economies A. Raw Daily Data for All Days, Including Weekends and Holidays

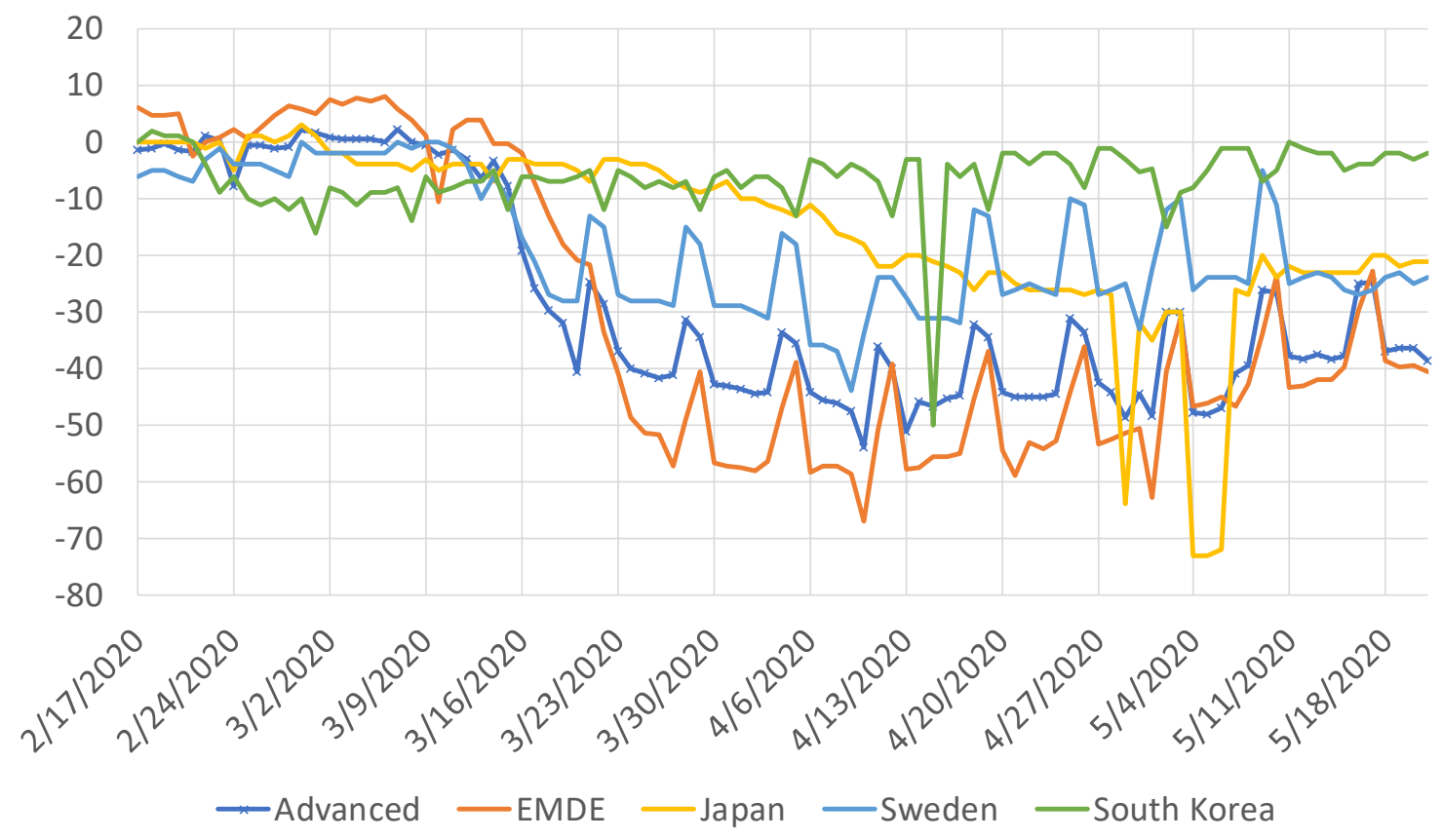

B. Seven-Day Moving Average of All Days, Including Weekends and Holidays

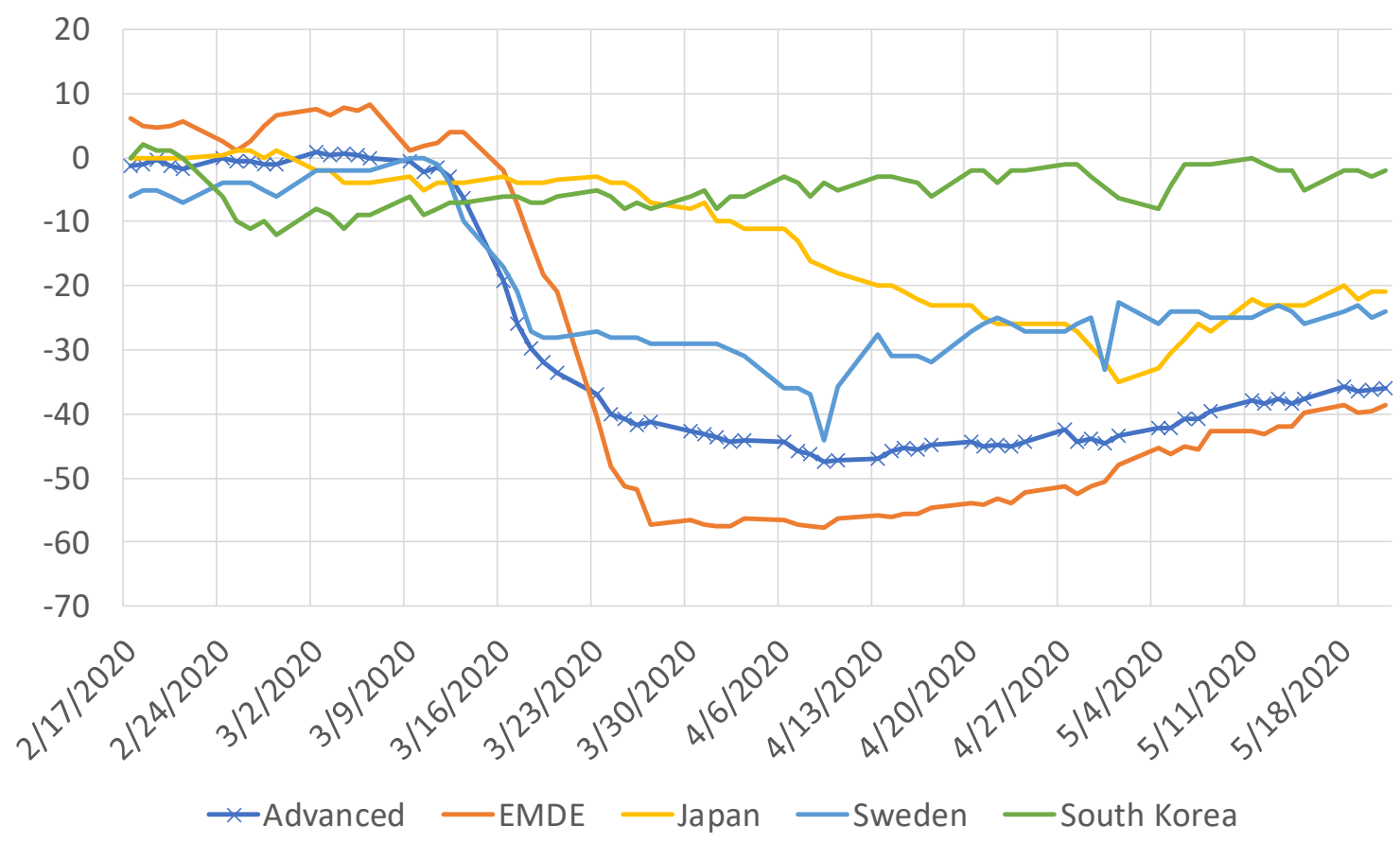


Figure A.2. Stringency of Economic Lockdown Measures, 17 February to 21 May 2020
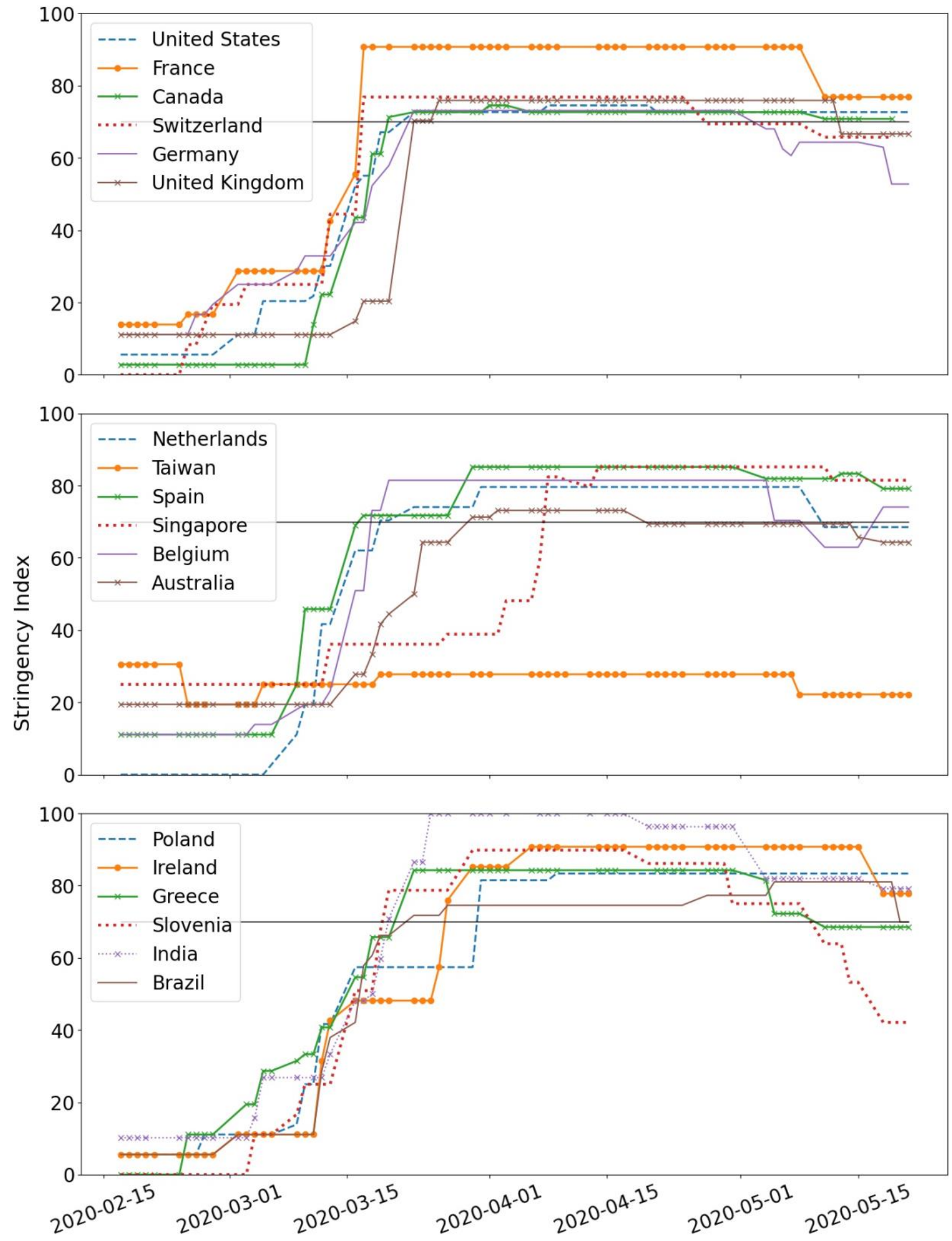

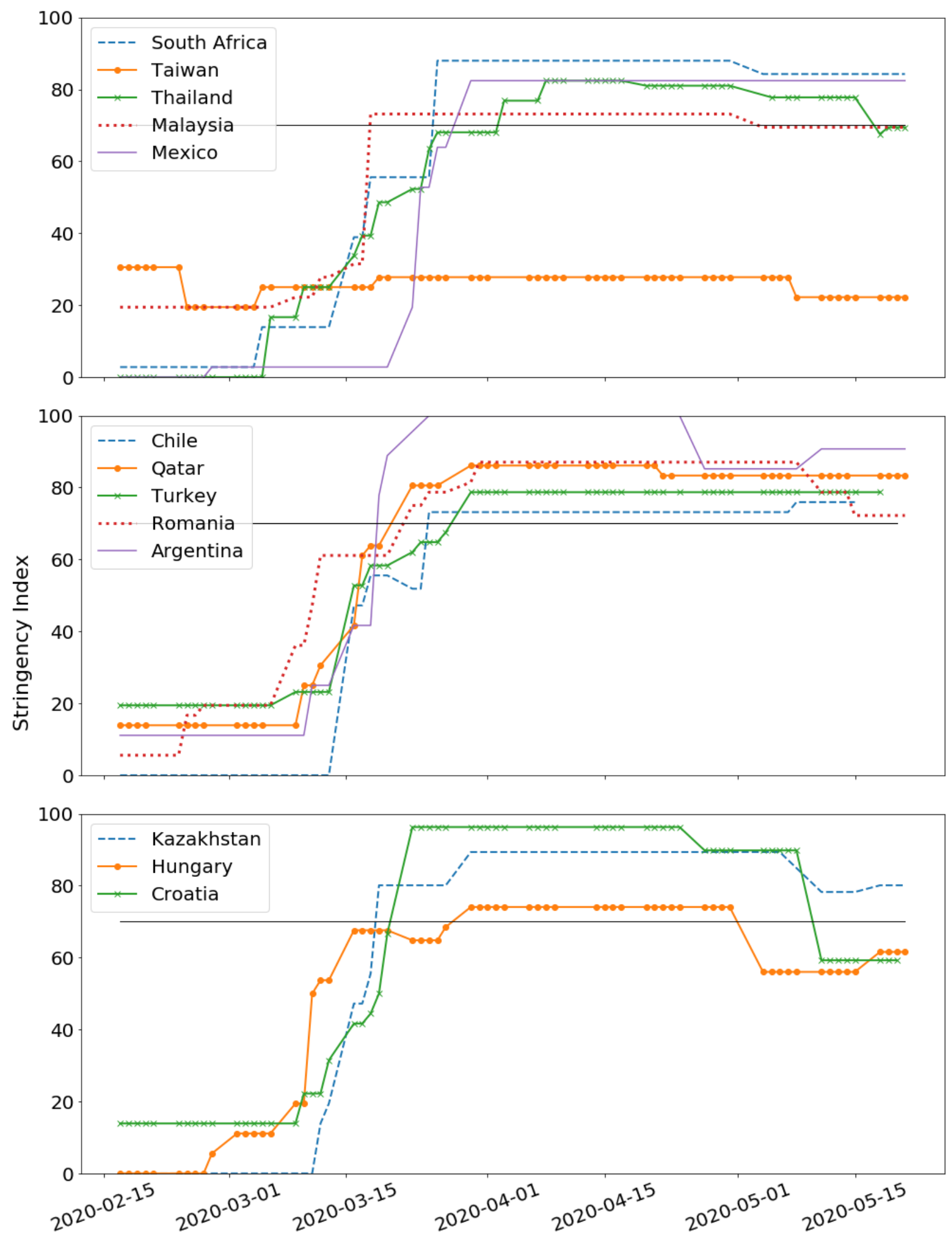

Note: We plot the Stringency Index from 17 February to 21 May 2020. The horizontal black line indicates the Stringency Index level of 70. The order the countries is based on the market cap on 31 December. 
Figure A.3. Time Path of Stock Prices and Workplace Mobility from 17 February to 21 May, Additional Countries

$$
\text { Greece }(0.07 \%) \quad \text { Slovenia }(0.01 \%)
$$

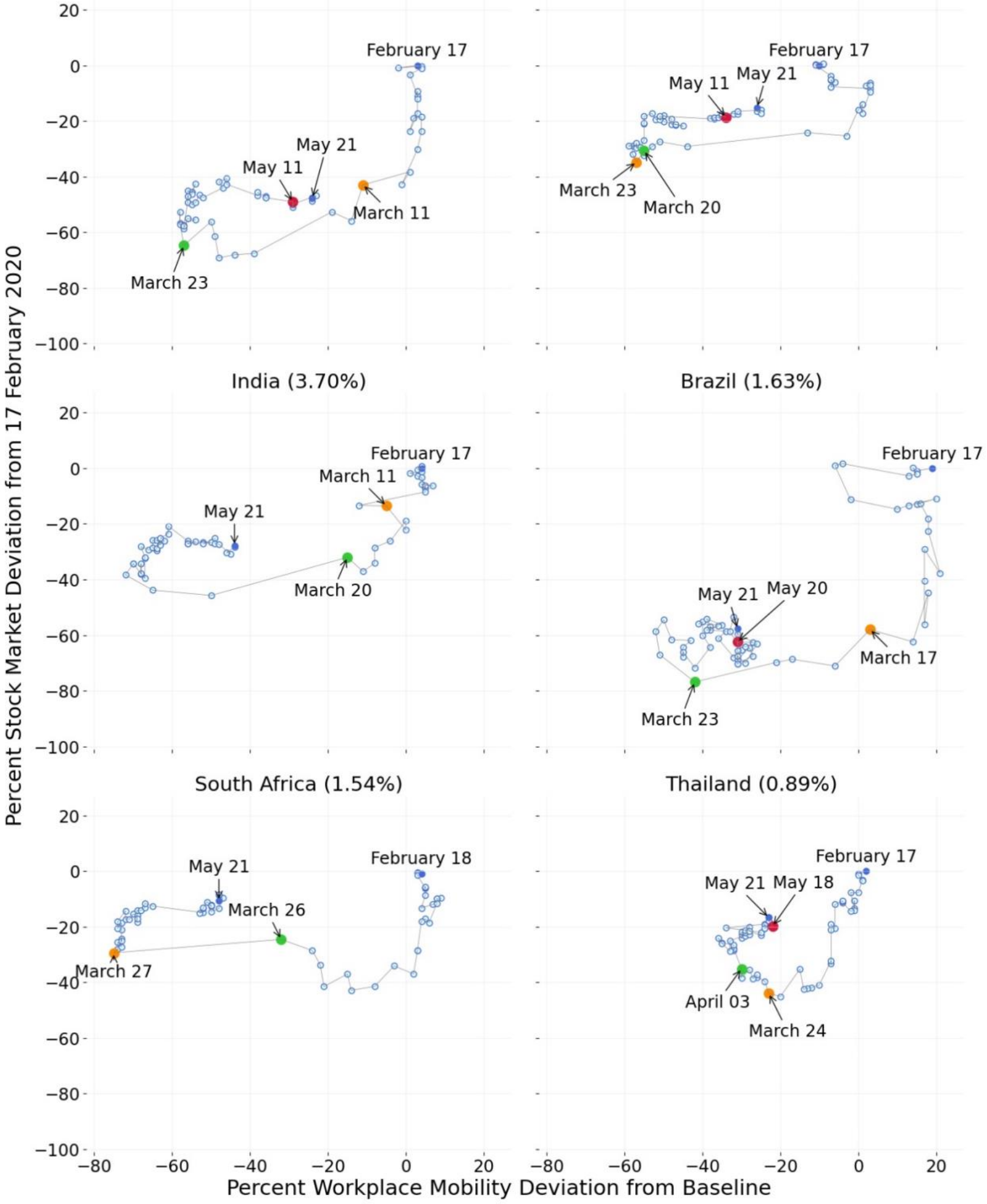


Malaysia $(0.71 \%)$

$20-$
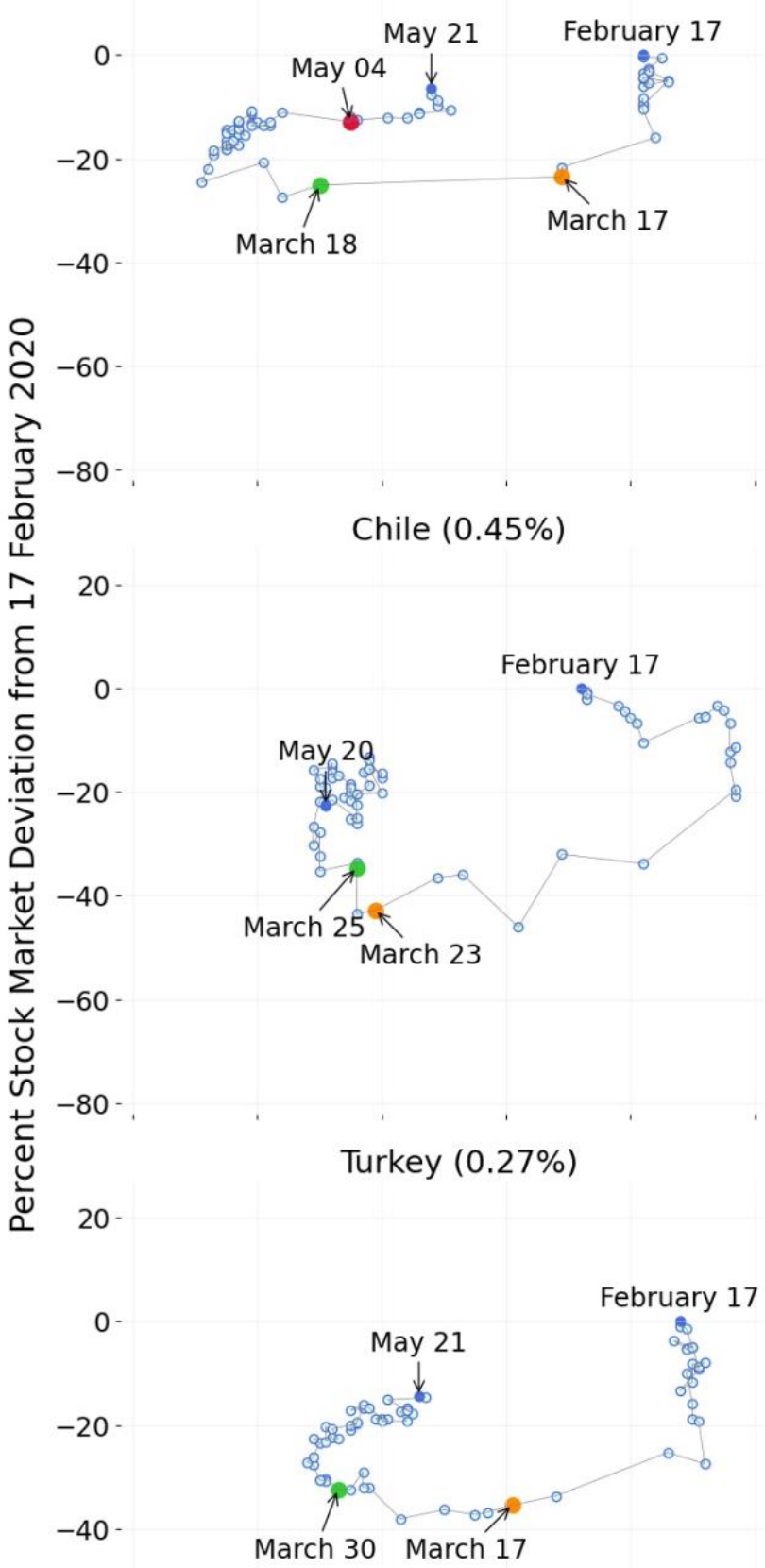

$-60-$

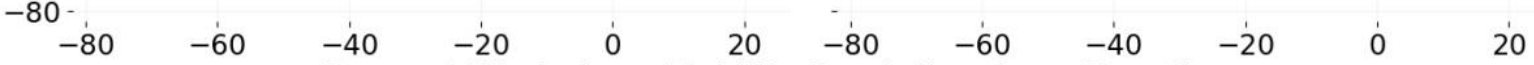

$$
\begin{aligned}
& \text { Percent Workplace Mobility Deviation from Baseline }
\end{aligned}
$$

Mexico $(0.68 \%)$

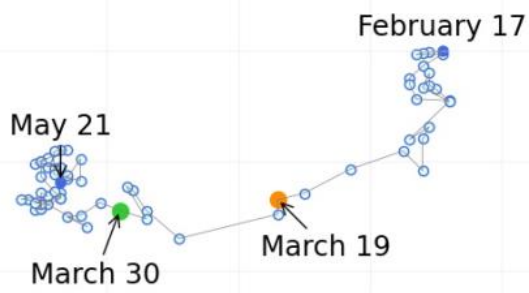

$$
\text { Qatar (0.29\%) }
$$

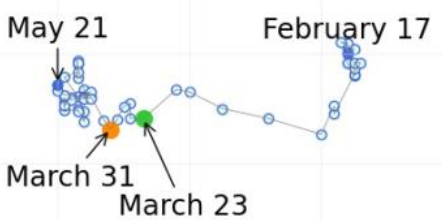

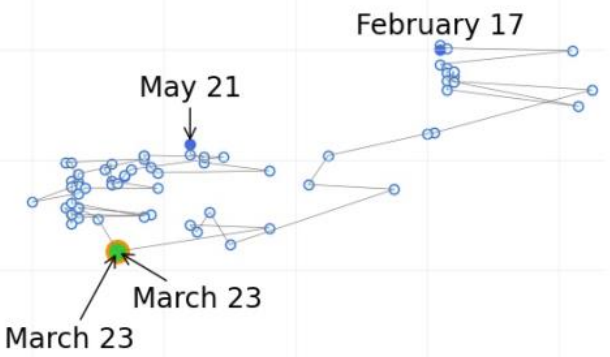


Argentina (0.08\%)

$20-$

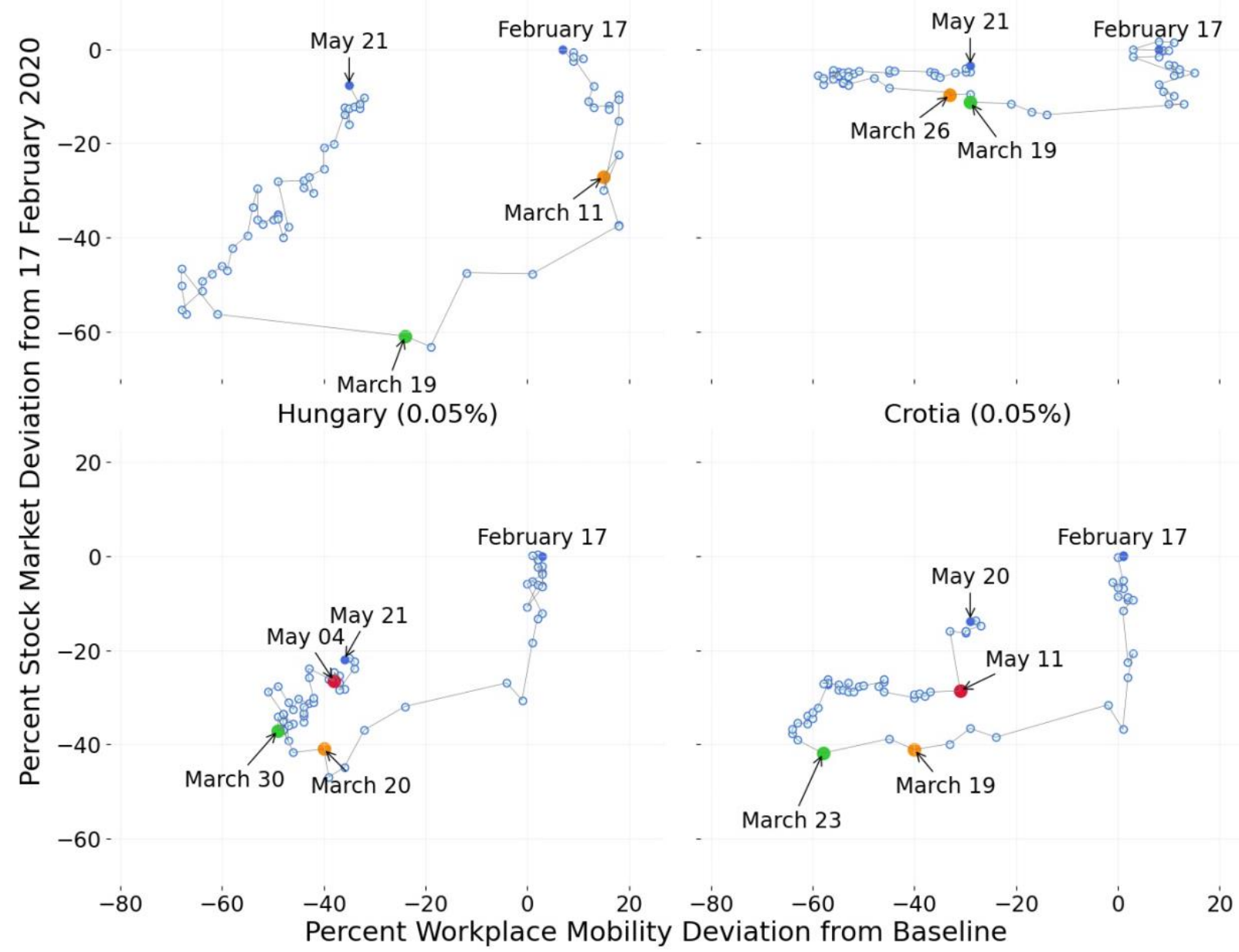


Figure A.4. Daily Doubling Time by Countries from 17 February to 31 August 31 Argentina
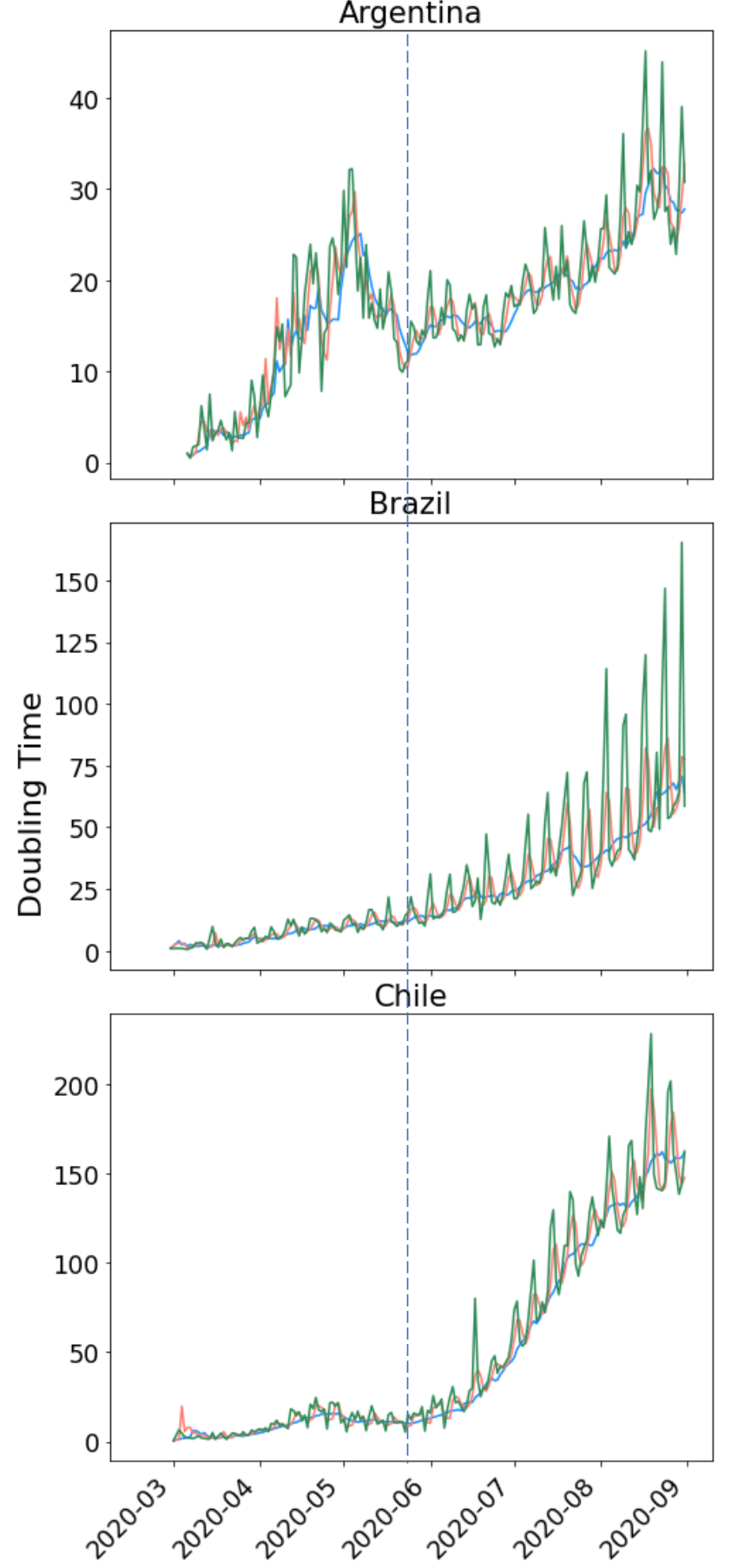

Belgium
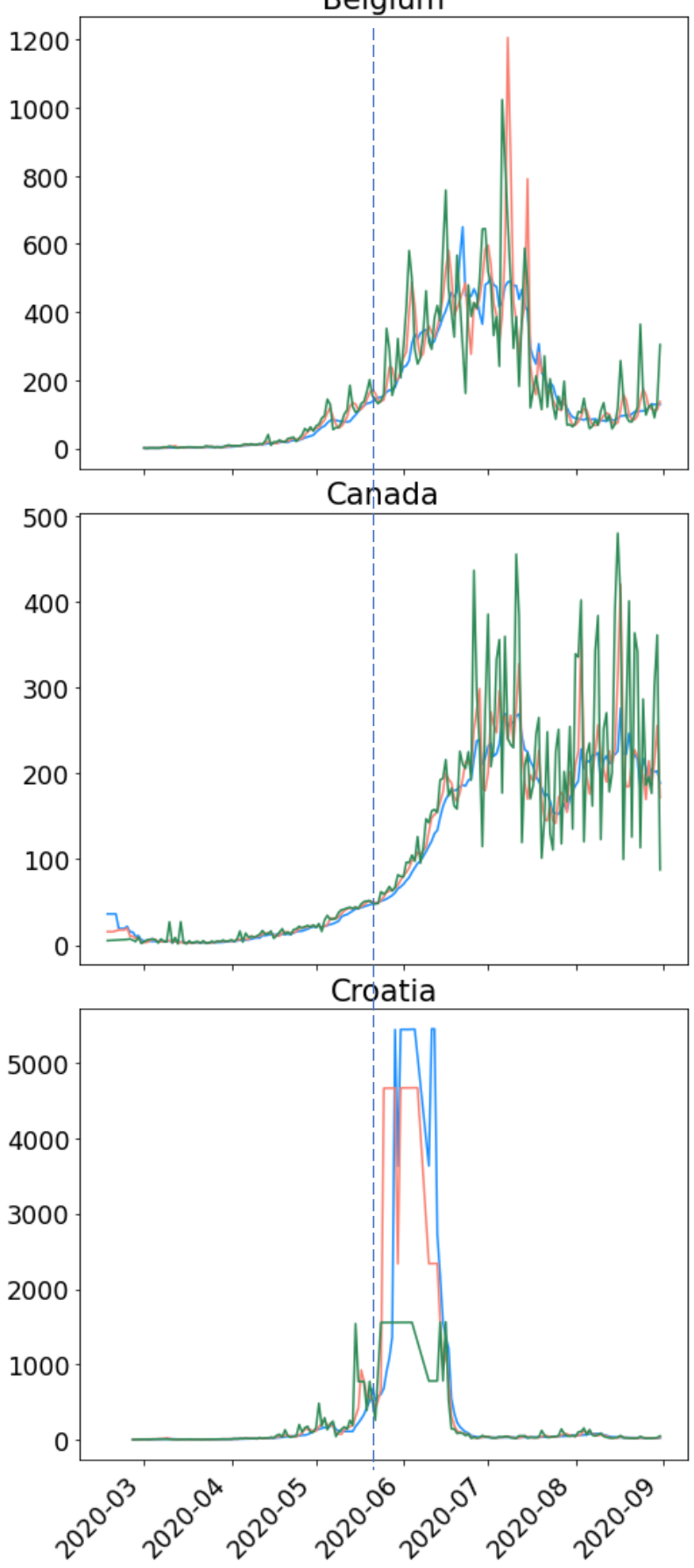
France
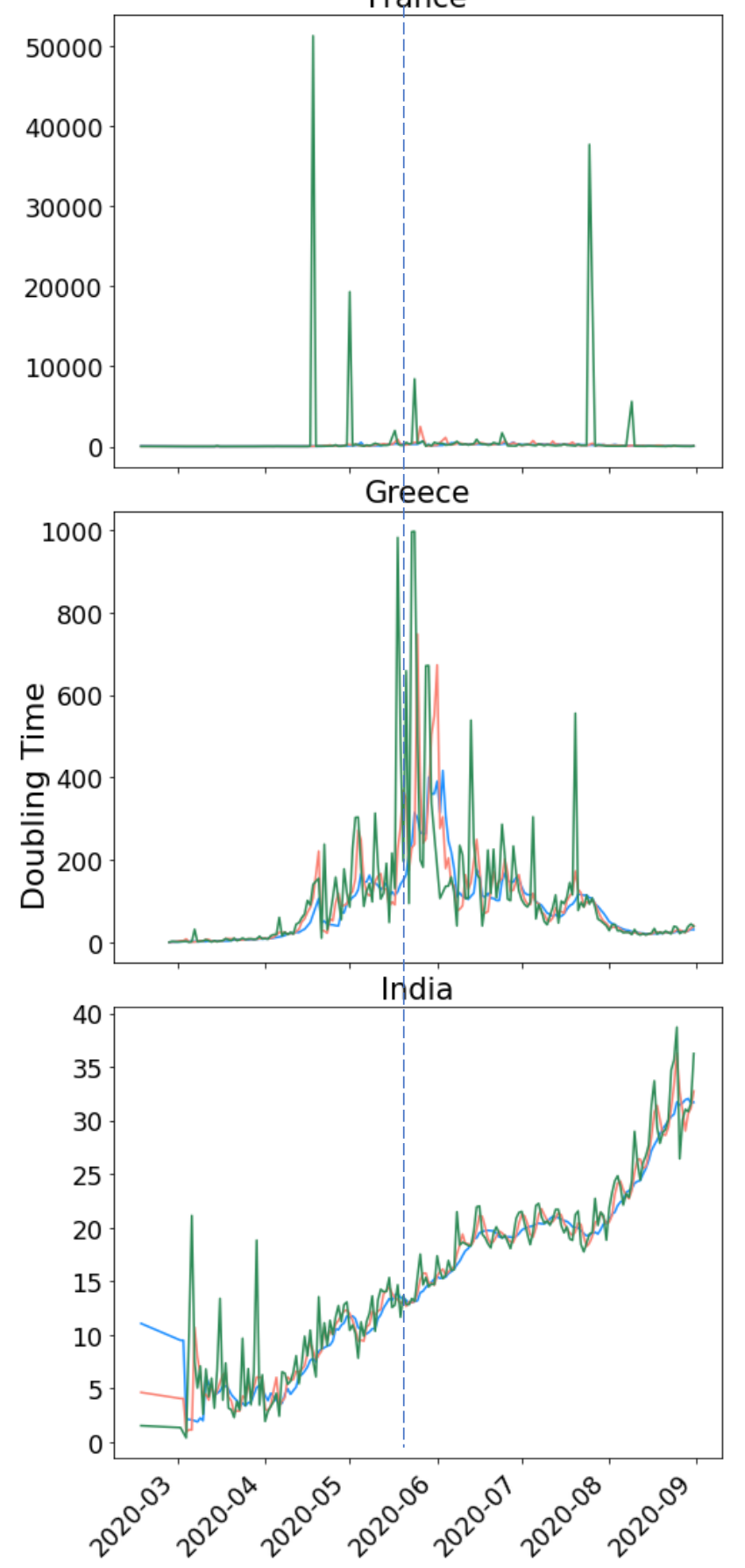
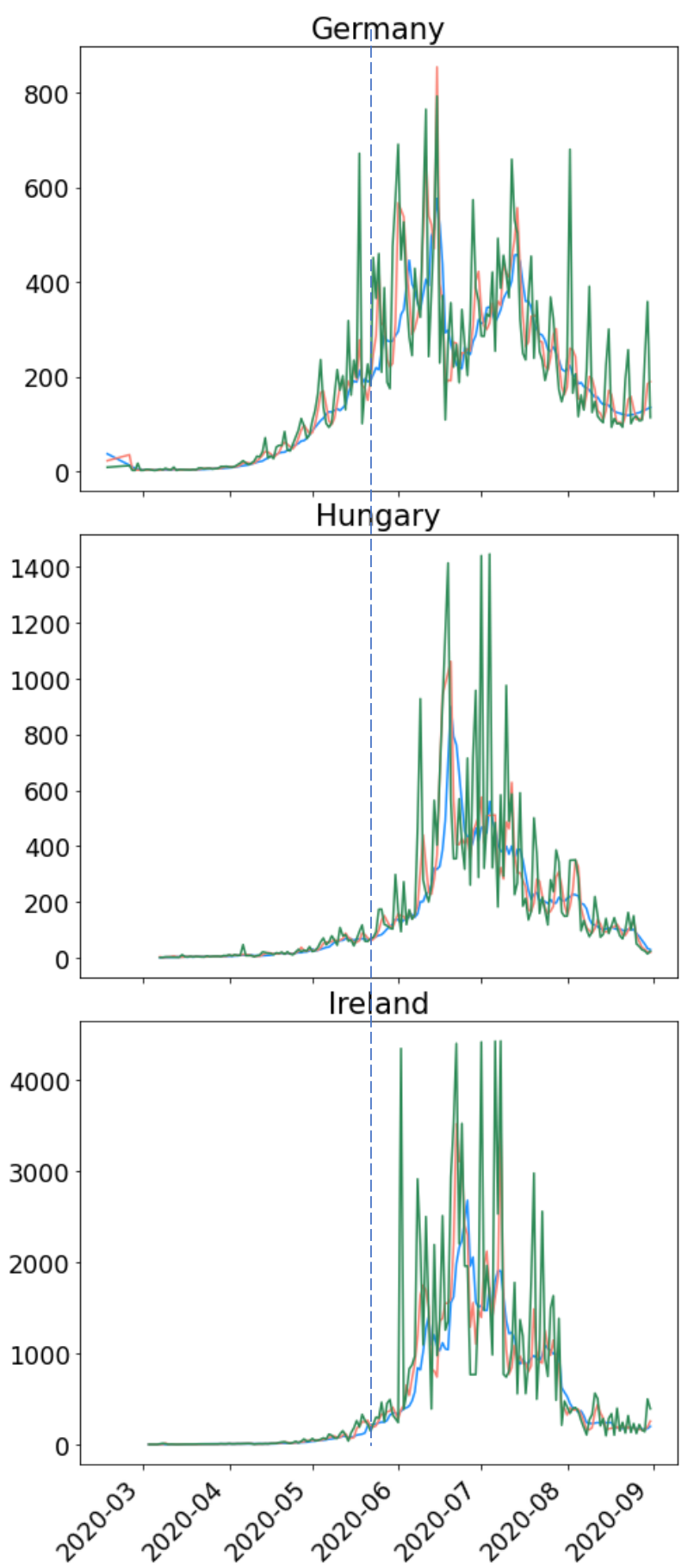

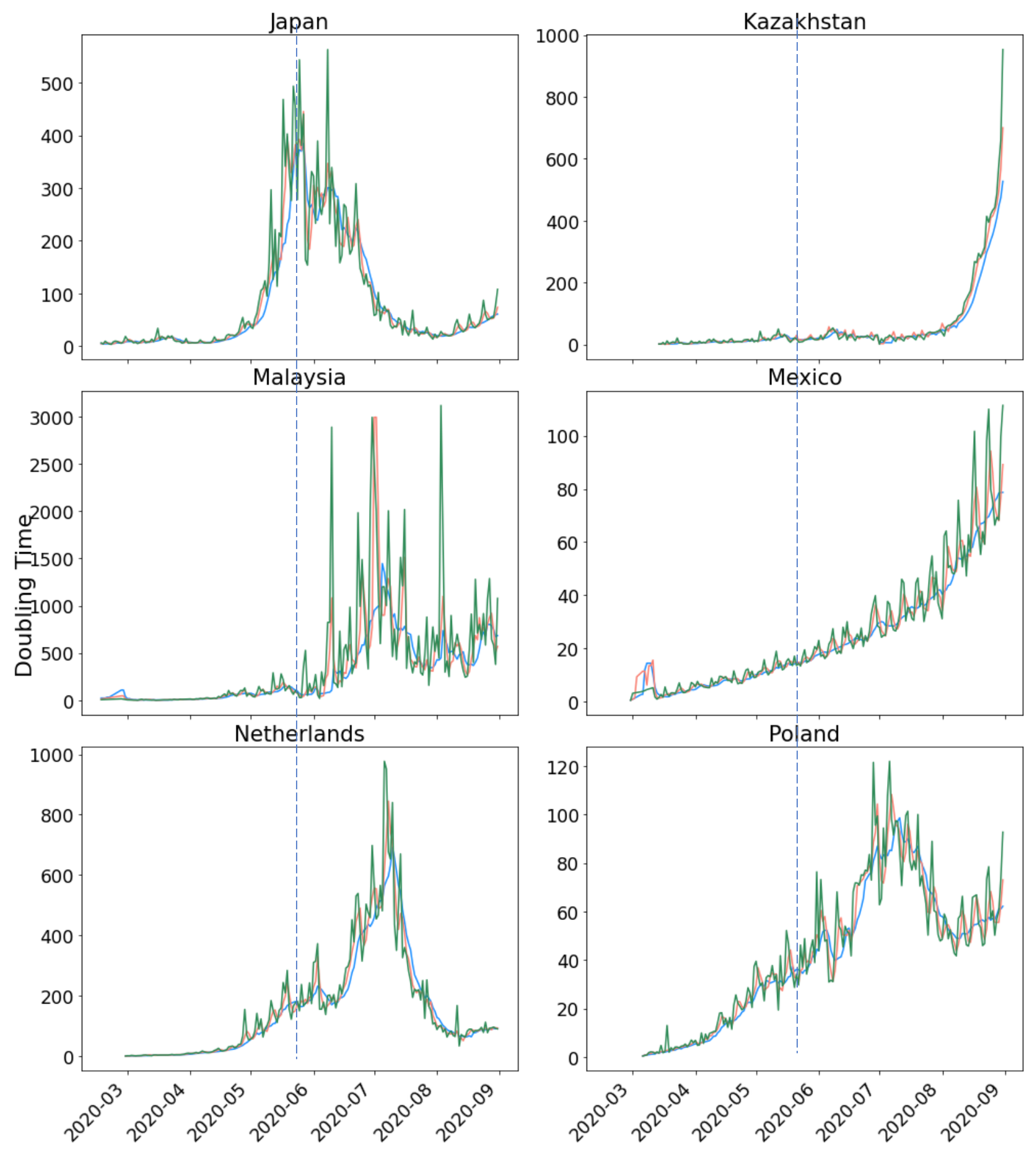

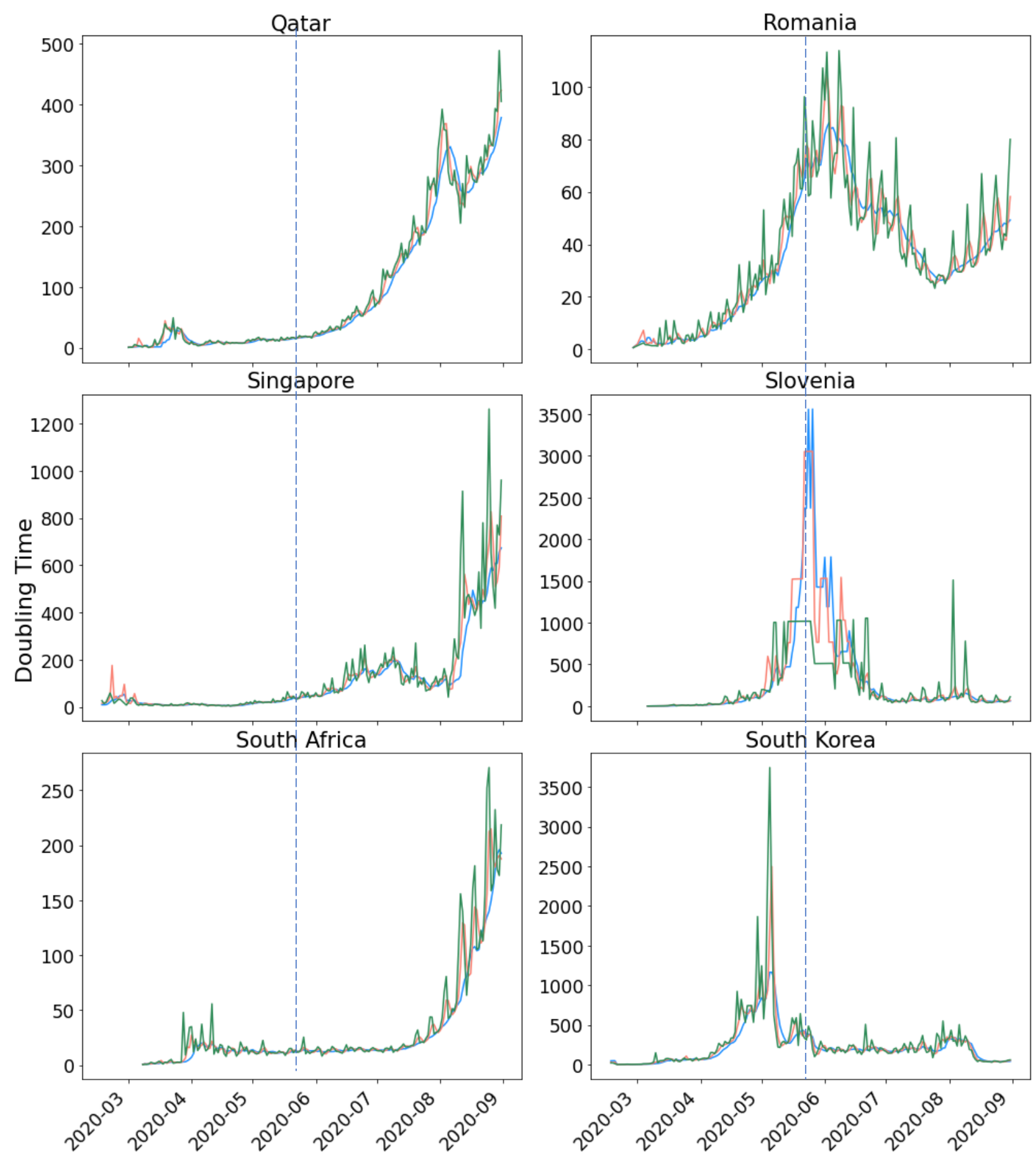

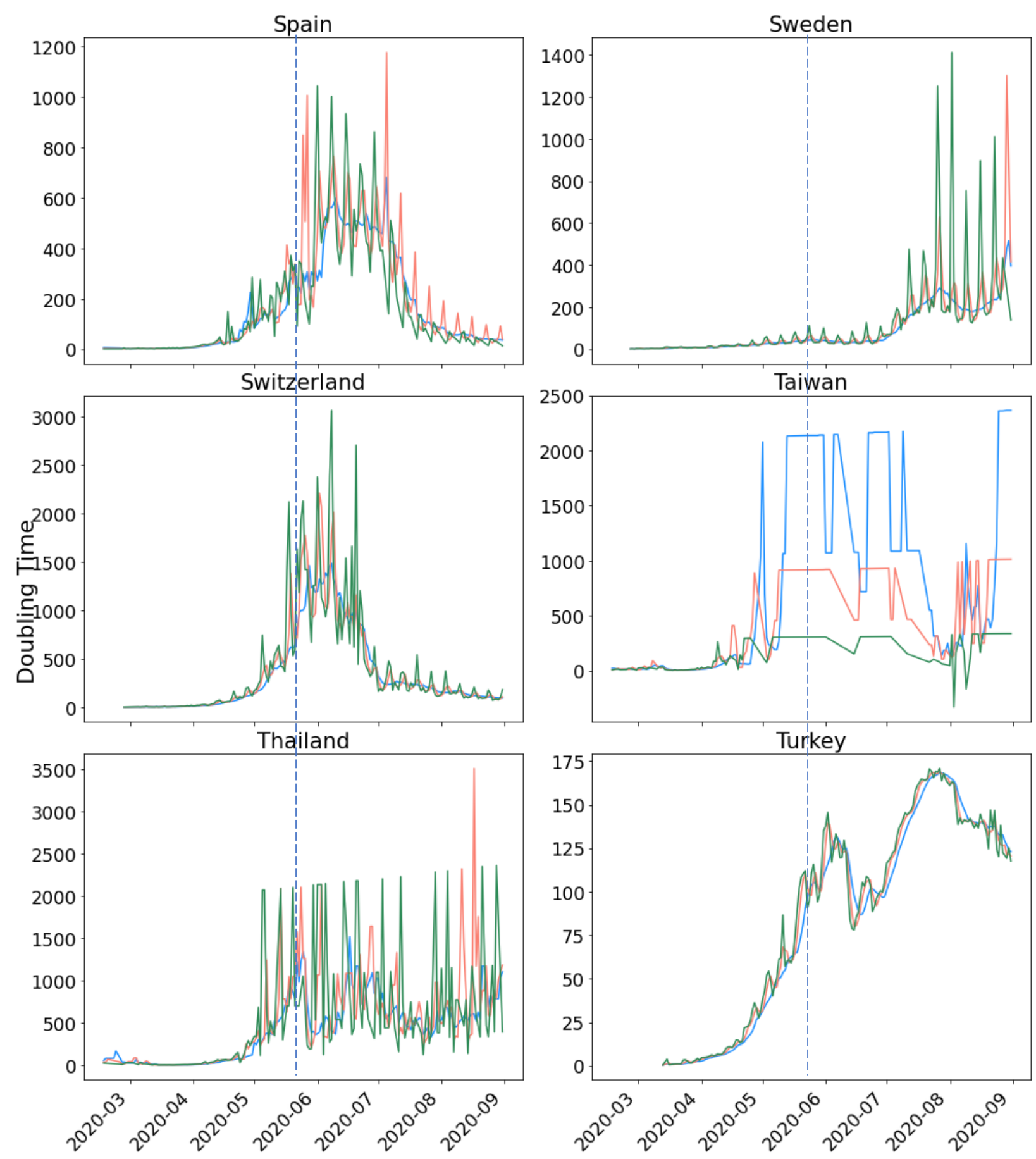


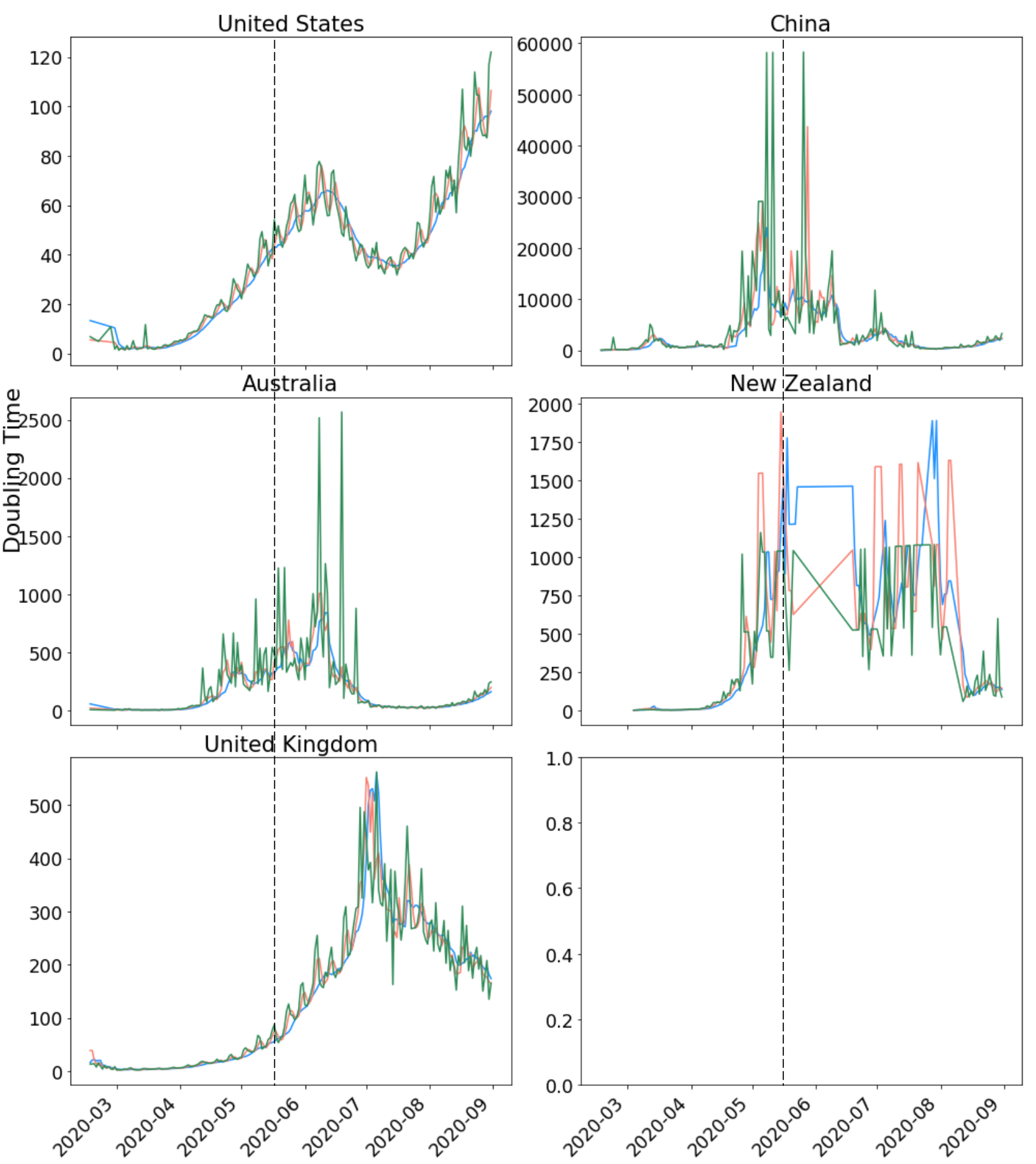

Note: We use Johns Hopkins Covid-19 database for confirmed cases. Blue line represents the doubling time based on the growth rate of the past seven days. Orange line shows the doubling time according to the past three days' growth rate. Green line presents the doubling time from the daily growth rate. Spain, France and Japan modified the methods of counting confirmed cases, resulting in decreased number of cases and a negative doubling time for some days. To fix this issue, we interpolate the doubling time for these days. When no new confirmed cases occur for a few days, there are missing values in the constructed doubling time and we impute these values using interpolation. 
Table A.1. Summary Statistics for Variables Used in Table 2 Regressions

\begin{tabular}{|c|c|c|c|c|c|c|c|}
\hline & mean & $\begin{array}{l}\text { St. } \\
\text { Dev. }\end{array}$ & $\min$ & $\begin{array}{c}25^{\text {th }} \\
\text { Centile }\end{array}$ & Median & $\begin{array}{c}75^{\text {th }} \\
\text { centile }\end{array}$ & $\max$ \\
\hline$W M D_{c, t}$ & -28.5 & 26.3 & -84 & -50 & -35 & -4 & 34 \\
\hline$S M D_{c, t}$ & -21.7 & 14.2 & -76.8 & -30.5 & -21.3 & -11.4 & 2.1 \\
\hline Deaths per Million & 1.4 & 3.5 & 0 & 0 & 0.0 & 0.9 & 36.3 \\
\hline Log (Doubling Time) & 2.6 & 1.6 & -1.1 & 1.5 & 2.4 & 3.5 & 8.2 \\
\hline $\begin{array}{l}\text { Economic Support } \\
\text { Index }\end{array}$ & 40.3 & 36.0 & 0 & 0 & 38.0 & 75 & 100 \\
\hline Stringency Index & 54.6 & 30.9 & 0 & 25 & 70.8 & 81.5 & 100 \\
\hline$\sum_{c} \omega_{c} W M D_{c, t}$ & -28.7 & 19.8 & -48.7 & -44.6 & -38.1 & -1.1 & 2.03 \\
\hline$\sum_{c} \omega_{c} S M D_{c, t}$ & -19.8 & 9.4 & -40.4 & -25.7 & -19.7 & -15.9 & 0.1 \\
\hline $\begin{array}{c}\text { Deaths } \\
\sum_{c} \omega_{c} \text { per Million } \\
\end{array}$ & 2.4 & 2.1 & 0 & 0.01 & 2.4 & 3.8 & 6.3 \\
\hline$\sum_{c} \omega_{c}$ Stringency & 52.8 & 24.4 & 9.4 & 23.9 & 67.9 & 70.2 & 73.1 \\
\hline $\begin{array}{c}\text { Economic } \\
\sum_{c} \omega_{c} \text { Support Index } \\
\end{array}$ & 41.3 & 29.4 & 0.6 & 3.3 & 60.9 & 65.7 & 68.1 \\
\hline
\end{tabular}

Notes:

1. The sample covers 2012 daily observations for 34 countries in the period from 17 February to 21 May 2020. The sample size is somewhat smaller (and excludes France) for Log (Doubling Time), as explained in the notes to Table 2.

2. $\omega_{c}$ is the country- $c$ share of aggregate stock market capitalization of the 34 countries as of 31 December 2018. The countries are listed in Section 2.A in the main text.

3. See Section 2.A in main text for variable definitions and data sources. 


\section{Appendix B. Constructing Implied Equity Market Volatility for China}

The Shanghai Stock Exchange (SSE) and China Securities Index Co (CSI) once published an official China VIX (iVX). The authorities suspended publication of the iVX in 201. Reuters (2018) suspects it was part of an effort by regulators to curb speculative trading and shore up investor confidence. To measure the implied volatility of China's stock market, we consulted the CBOE VIX White Paper and the SSE's method for constructing the iVX. We constructed a VIXlike index for China based on SSE 50ETF options. Our China VIX behaves very similarly to the iVX during the overlapping period, with a correlation of 0.99 .

Here is a detailed description of how we constructed our China VIX measure:

1) Select SSE 50ETF options to be used in the China VIX Index calculation. The components of our China VIX are near- and next-term put and call SSE 50ETF options. SSE 50ETF Options provide four expiration months: Current month, next month and the following consecutive quarters. We select SSE 50ETF options with an expiration day somewhat longer than 7 days as near-term, and options with the next shortest expiration day as next-term. For example, on May 19, 2020, we calculate the China VIX Index using SSE 50ETF options expiring 8 days later (i.e., "near-term") and 36 days later (i.e., "next-term"). On the following day, the SSE 50ETF options that expire in 7 days would become the "near-term" options and SSE 50ETF that expire in 35 days later would be the "next-term" options. The final selected options are out-of-the-money SSE 50ETF calls and puts centered around the at-the-money strike price, $K_{0} .{ }^{1}$ We only select options with non-zero bid prices, so the number of options used in the calculation may vary.

2) Calculate time to expiration $T_{1}$ and $T_{2}$ for near- and next-term options using the expression:

$$
T=\frac{M_{\text {current day }}+M_{\text {settlement day }}+M_{\text {other days }}}{\text { Minutes in a year }}
$$

Where $M_{\text {current day }}$ represents minutes remaining until midnight of the current day, $M_{\text {settlement day }}$ calculates the minutes from midnight until 9:15 am (GMT+8), and $M_{\text {other days }}$ counts total minutes from the current day to the expiration day.

3) Determine the risk-free interest rates, $R_{1}$ and $R_{2}$ for near- and next-term options. The risk-free interest rates are yields based on Shanghai Interbank Offered Rate (SHIBOR). We apply a cubic spine to derive yields on the expiration dates of relevant SSE 50ETF options.

4) Determine the forward SSE 50ETF level, $F_{1}$ and $F_{2}$, by identifying the strike price $K_{0,1}$ and $K_{0,2}$ at which the absolute difference between the call and put prices in smallest for near- and next-term options:

$$
\begin{aligned}
& F_{1}=K_{0,1}+e^{R_{1} \times T_{1}} \times\left(\text { Call Price }_{1}-\text { Put } \text { Price }_{1}\right) \\
& F_{2}=K_{0,2}+e^{R_{2} \times T_{2}} \times\left(\text { Call Price } 2-\text { Put } \text { Price }_{2}\right)
\end{aligned}
$$

5) Select out-of-the-money put options with strike prices less than $K_{0,1}$ for near-term option and put options with strike prices less than $K_{0,2}$ for next-term option. Similarly, select the out-of-themoney call options with strike prices more than $K_{0,1}$ for near-term options and put options with strike prices more than $\mathrm{K}_{0,2}$ for next-term options. We exclude call and pull options with zero bid prices. Finally, we select both the put and call with strike price $K_{0}$.

6) Calculate volatility for both near-term and next-term options according to

\footnotetext{
${ }^{1}$ SSE 50ETF Options offer nine strike prices (1 at-the-money, 4 out-of-the-money and 4 in-the-money),
} see http://english.sse.com.cn/markets/derivatives/overview/. 


$$
\begin{gathered}
\sigma_{1}^{2}=\frac{2}{\mathrm{~T}_{1}} \sum_{i} \frac{\Delta K_{i}}{K_{i}^{2}} \mathrm{e}^{\mathrm{R}_{1} \times \mathrm{T}_{1}} \mathrm{Q}\left(K_{i}\right)-\frac{1}{\mathrm{~T}_{1}}\left[\frac{F_{1}}{K_{0,1}}-1\right]^{2} \\
\sigma_{2}^{2}=\frac{2}{\mathrm{~T}_{2}} \sum_{i} \frac{\Delta K_{i}}{K_{i}{ }^{2}} \mathrm{e}^{\mathrm{R}_{2} \times \mathrm{T}_{2}} \mathrm{Q}\left(K_{i}\right)-\frac{1}{\mathrm{~T}_{2}}\left[\frac{F_{2}}{K_{0,2}}-1\right]^{2}
\end{gathered}
$$

Where $\Delta K_{i}$ is half the difference between the strike prices on either side of $K_{i} \cdot \mathrm{Q}\left(K_{i}\right)$ is the midpoint of the bid-ask spread for each option with strike $K_{i}$.

7) Calculate the 30-day weighted average of $\sigma_{1}^{2}$ and $\sigma_{2}^{2}$. Then take the square root of that value and multiply by 100 to get our China VIX Index value.

$$
\text { China VIX }=100 \times \sqrt{\left\{\mathrm{T}_{1} \sigma_{1}^{2} \times \frac{M_{\mathrm{T}_{2}}-M_{30}}{M_{\mathrm{T}_{2}}-M_{\mathrm{T}_{1}}}+\mathrm{T}_{2} \sigma_{2}^{2} \times \frac{M_{30}-M_{\mathrm{T}_{1}}}{M_{\mathrm{T}_{2}}-M_{\mathrm{T}_{1}}} \times \frac{M_{365}}{M_{30}}\right.}
$$

where $M_{\mathrm{T}_{1}}$ is the number of minutes to settlement of the near-term options, $M_{\mathrm{T}_{2}}$ is the number of minutes to settlement of the next-term options, $M_{30}$ represent the number of minutes in 30 days and $M_{365}$ is the number of minutes in a 365-day year. 